\title{
Métodos de determinar a idade fisiológica em Diptera de importância médica. Úma revisào com especial referência aos vetores de doenças na América do Sul.
}

\author{
J. D. Charlwood (") \\ J. A. Rafael (*) \\ T. J. Wilkes $\left({ }^{* *}\right)$
}

\section{Resumo}

Os métodos de determinar a idade fisiológica em Diptera hematófagos de importância médica, que mostram concordância gonotrófica, são revisados. Na primeira parte, são delineadas as mudanças que ocorrem no inseto, após o repasto sangüíneo e discutida a base teórica para determinação da idade fisiológica. Na segundo parte, são dados os métodos aplicáveis a Culicidae, Simuliidae, Phlebotomidae, Ceratopogonidae e Tabanidae. Amplo uso de material fotográfico é adotado, dando proveitoso auxilio na interpretação da disseceçẳo do ovário.

A determinação da idade fisiológica em Diptera hematófagos é de interesse tanto prático como teórico. A importância prática está no fato de que, em geral, somente insetos velhos são vetores de doenças e um conhecimento da idade da população permite que a importância epidemiológica seja taxada. Possibilita também determinar as causas da mudança na composição adulta.

O conhecimento da idade fisiológica numa população adulta de inseto fornece informações sobre a taxa de sobrevivência diária, a qual biologistas teóricos usam para formular e testar modelos de dinâmica populacionais e problemas afins (Macdonald, 1957; GarrettJones \& Shidrawi, 1969).

Mudanças no comportamento e na distribuição devidos à idade podem ser importantes epidemiologicamente. Essas mudanças somente podem ser detectaaas se a estrutura da ida. de fisiológica da população for determinada. Diferenças entre fêmeas jovens e velhas que chegam para picar podem resultar em ciclos bifásicos, nos quais as mudanças dos seres infectados variam. (Chariwood \& Wilkes, 1979; Ducke, 1968a). Insetos com idades diferentes podem apresentar várias distribuições. Por exemplo, em algumas espécies de mosquitos, os mais velhos tendem a voar mais alto e dispersar mais do que os jovens (Snow \& Wilkes, 1977).

A compreensão das mudanças numa população de insetos é particularmente importante em áreas que apresentam uma incidência sazonal de moléstias acentuada como a malária no Amazonas, Brasil. A estrutura dinâmica da população de insetos pode ser o fato mais importante envolvido na dispersão e incidência desta moléstia em tais áreas, epidemiologicamente instáveis.

Antigamente, quando a determinação da idade dependia de métodos primitivos (Perry, 1912), os dados obtidos não eram precisos. A possibilidade de determinar-se, com precisão a idade fisiológica de muitos dípteros hematófagos significa que podem ser obtidos dados sobre a biologia, ecologia e importância epidemiológica das populações.

As mudanças que ocorrem no sistema reprodutivo feminino já foram estabelecidas por entomologistas trabalhando na Rússia (ver Detinova, 1962). Essas mudanças fisiológicas associadas com o desenvolvimento do ovo fornece a base para a determinação da idade fisiológica, incluindo aquelas que são repetidas durante o desenvolvimento de cada lote de ovos e que consistem em alterações irreversí. veis nos órgãos reprodutivos.

(*) - Instituto Nacional de Pesquisas da Amazônia, Manaus.

("*) - Mosquito Behaviour Unit, School of Biology, University of Sussex, Great Britain. 
Revisões e descrições de técnicas de determinar a idade fisiológica já foram realizadas por Detinova (1962), Gillies (1958), Forattini, (1962) e Service (1976), entre outras.

Mosquitos e outros Orthorrapha são caracterizados por concordância gonotrófica; isso significa que a cada repasto sangüineo completo, um lote de ovos se desenvolverá. O número de ciclos gonotróficos realizados pela fêmea representa sua idade fisiológica.

O sistema reprodutivo das fêmeas de mosquitos consiste de dois ovários e ductos associados, localizados entre o $4 .^{\circ}$ e $5 .^{\circ}$ segmentos abdominais (Fig. 1). Durante a maturação dos ovos, há o crescimento dos mesmos, ocupando toda a cavidade abdominal do $1 .^{\circ}$ ao $7 .^{\circ} \mathrm{seg}$ mentos. Cada ovário está envolto por uma membrana externa que termina proximalmente no processo terminal. Os ovidutos laterais, dos quais saem os ovaríolos radialmente, conectam-se para formar o oviduto comum. Abrindo-se no oviduto comum, estão as glândulas acessórias e as espermatecas (Fig. 1) que são usadas para armazenamento de esperma.

O número de ovaríolos não são constantes e variam de 50 a 100 por ovário. Cada ovaríolo consiste em um germário, do qual brotam os sucessivos folículos de uma bainha do ovaríolo, bem junto à túnica, e duma parede do tubo folicular. A bainha do ováríolo contém núcleos esparsos e finas faixas musculares. Depois do desenvolvimento normal do folículo, ela forma uma larga conexão ao redor do pedicelo do tubo folicular e continua até ao cálice. Em fêmeas gonoativas, dois folículos são normal. mente visíveis. Um, bem aderente ao germário, enquanto o outro se localiza mais próximo ao oviduto lateral. Este último desenvolve-se depois de um repasto sangüíneo (Fig. 2) .

Em fêmeas recém-emergidas, somente um folículo indiferenciado é visível, mas, depois de um certo tempo, usando reservas trazidas do estágio larval ou recursos de uma alimentação de carboidrato, um segundo folículo começa a desenvolver-se e torna-se visível.

Os ovários são do tipo meroístico politrófico, onde os trofócitos suprem o cócito com RNA e orgânulos através de canalículos intercelulares, durante a maior parte de seu desenvolvimento. Observações minuciosas da ovogênese em microscópio eletrônico foram feitas em muitas espécies de mosquitos (Roth, 1966; Fiil, 1974, 1976; Fiil \& Moens, 1973). Isso tem confirmado, em grande parte, as observações
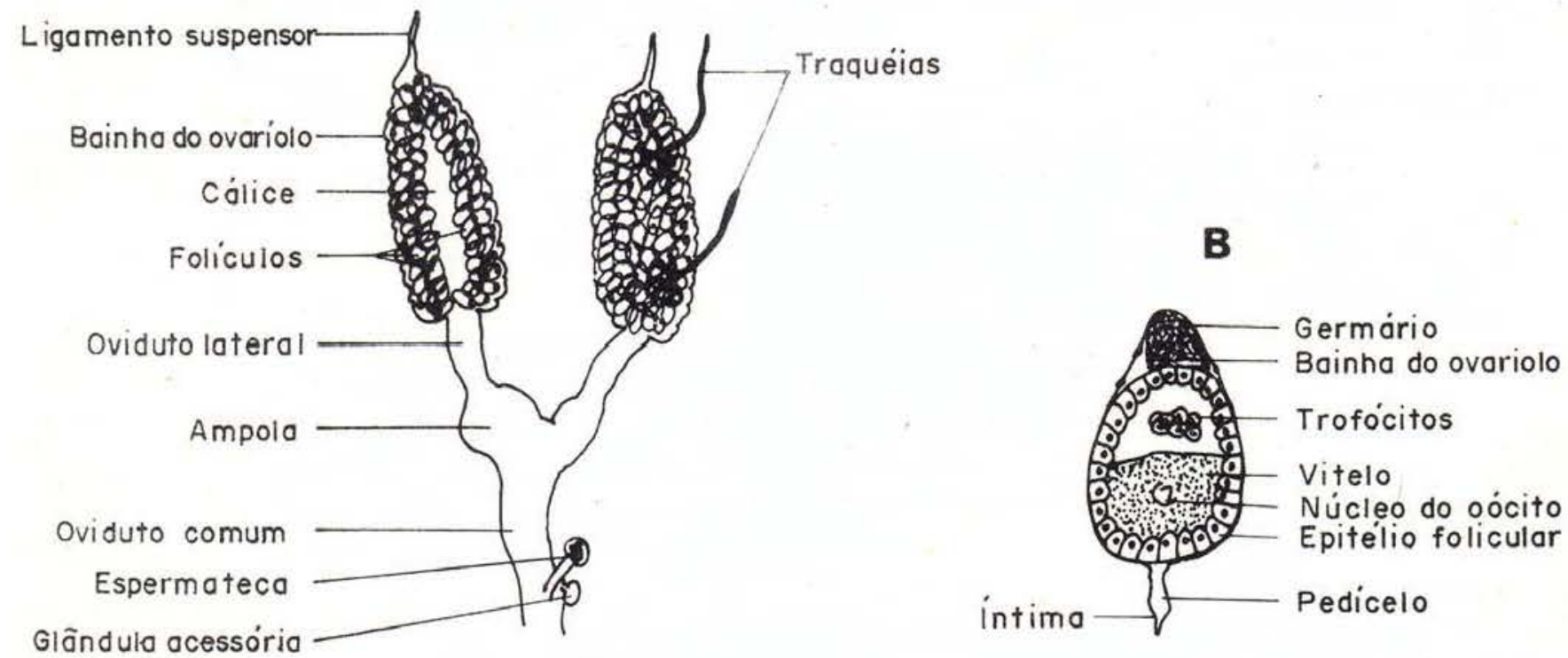

A

Fig. 1-A. Diagrama mostrando a estrutura do aparelho reprodutor de uma fêmea de mosquito; B. Estrutura de um folículo. 


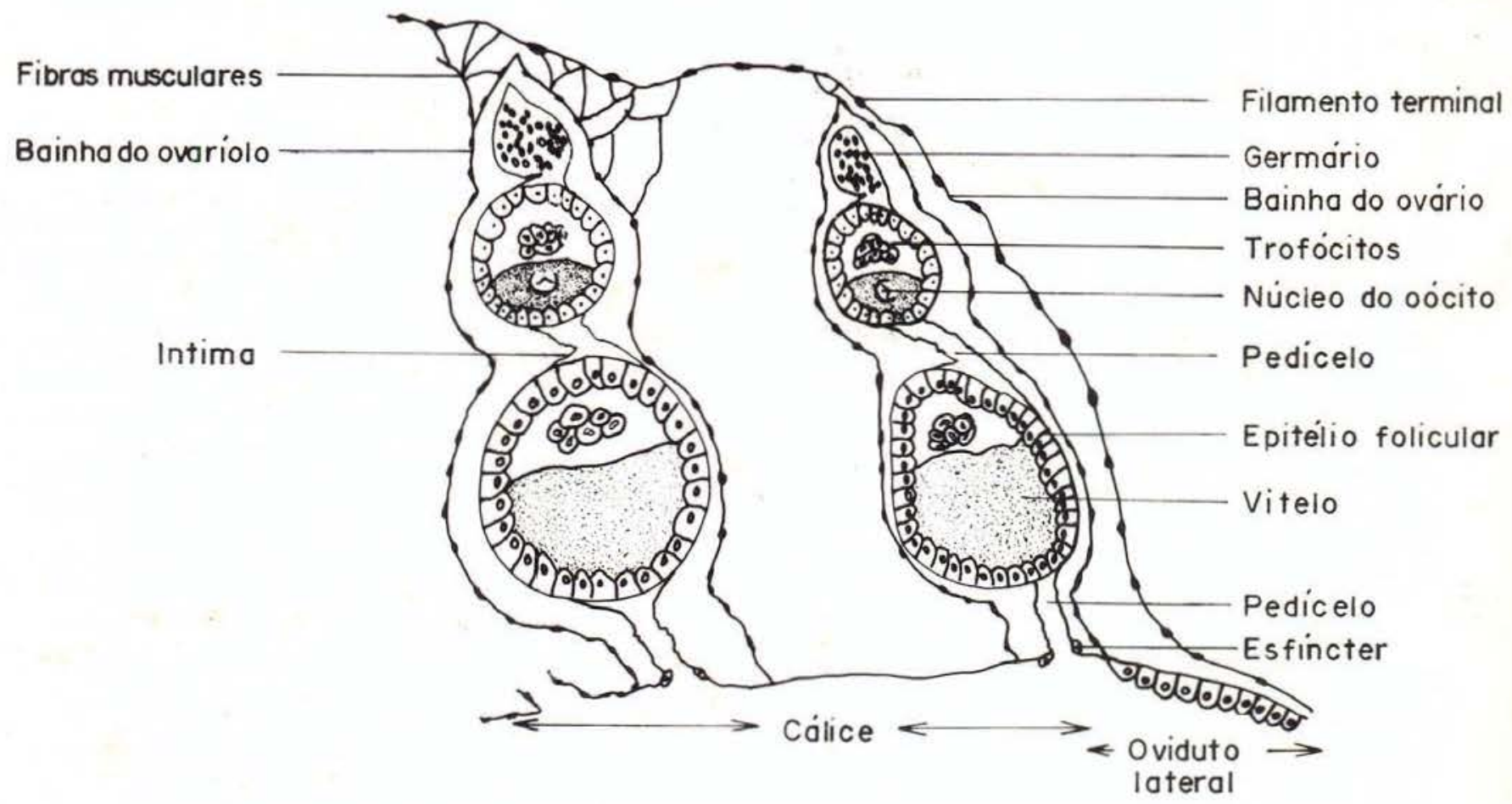

Fig. 2 - Corte longitudinal do ovário de uma fêmea nulípara mostrando a estrutura do ovaríolo.

de Nicholson (1921), demonstrando que nos primeiros estádios de desenvolvimento do folículo, oito células são visíveis (sete trofócitos e um oócito). O desenvolvimento do folículo está associado com um acúmulo de vitelo ao redor do oócito, que em seu gradual desenvolvimento, empurram os trofócitos para sua extremidade proximal. Nos últimos estádios, o folículo aumenta de tamanho e o oócito, cheic de vitelo, torna-se gradualmente maior e opaco. O folículo permanece transparente somente onde se localizam os trofócitos, e no final do desenvolvimento, os trofócitos ficam fora do córion.

Christophers (1911) , classificou o desenvolvimento em cinco estádios, os quais, com pequenas modificações feitas por Mer (1936) são ainda universalmente usados.

Os estádios são mostrados na fig. 3 e classificados de acordo com as seguintes características :

$$
\begin{aligned}
& \text { I - O folículo tem forma arredondada e } \\
& \text { não existe grânulos de vitelo. O } \\
& \text { oócito não é distinguível dos trofóci- } \\
& \text { tos, que aparecem, sob grande au- } \\
& \text { mento }(40 \mathrm{x}) \text {, em microscópio de }
\end{aligned}
$$

dissecação, como corpos arredondados translúcidos. Este estádio está associado com as fêmeas recémemergidas.

II - O folículo apresenta forma oval com grânulos de vitelo ao redor do oócito, que podem posteriormente ocupar metade do folículo. O oócito não está oculto. Este estádio foi dividido por Macan (1950) como se segue:

II - cedo: quando o vitelo é visível somente sob grande aumento no microscópio de dissecação $(40 x)$.

II - médio: quando o vitelo é facilmente visível sob baixo aumento $(10 \mathrm{x})$.

II - avançado: quando o vitelo é facilmente visível sob o mais baixo aumento (não mais que $(10 x)$.

III - O vitelo ocupa mais da metade do folículo, ainda oval. O núcleo no oócito está oculto. 


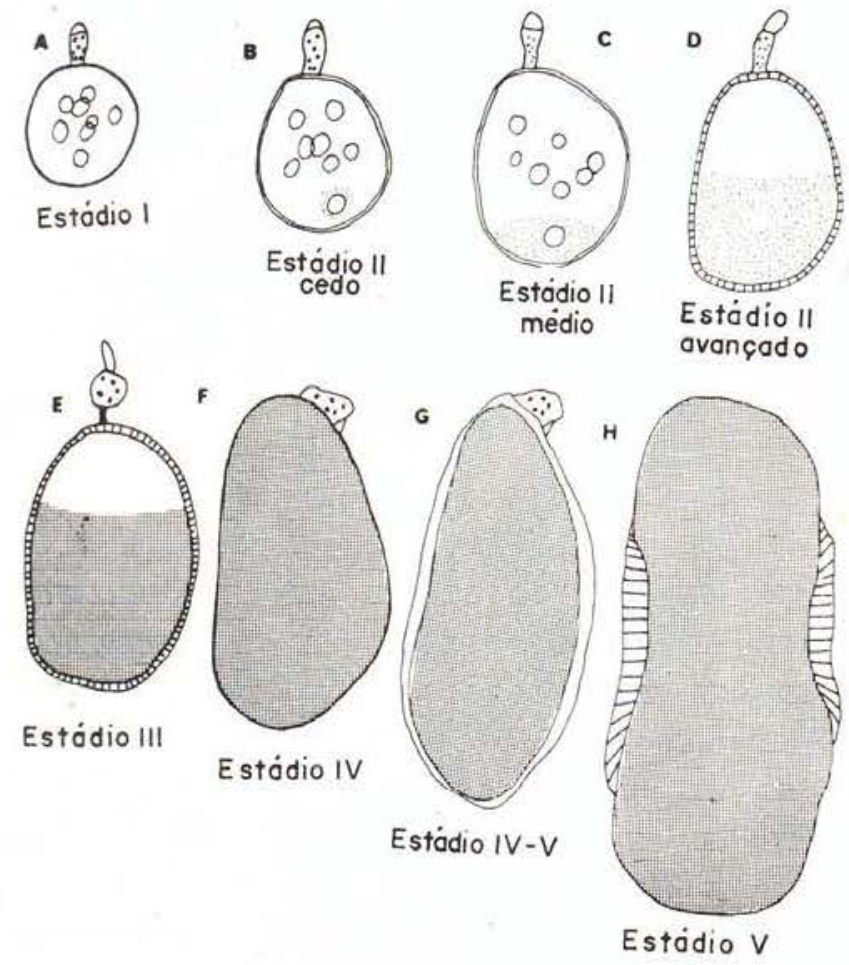

Fig. 3 - Diagrama mostrando a aparência de um foliculo nos diferentes estádios de Christophers em Anopheles $\mathrm{sp}$.

IV - O folículo torna-se maior e os trofócitos ocupam somente a sua parte superior. O oócito, cheio de vitelo. está bem desenvolvido e ocupa mais de $9 / 10$ do folículo.

$\mathrm{V}$ - O córion cobre todo o óvulo. Os restos dos trofócitos são encontrados na extremidade proximal do folículo. Em anofelinos, forma-se o flutuador. e o óvulo acha-se pronto para ser fecundado e ovipositado.

A ovogênese, pode ser dividida em três fases distintas: a primeira é marcada pelo surgimento do folículo do germário. Durante esta fase, um grupo de duas, quatro e oito células aparece na porção inferior do germário. Simultaneamente o epitélio começa a envolver o folículo recém-formado. Quando completado, ele se separa do germário. Na emergência, cada ovaríolo consiste normalmente em um folículo, acima do qual está situado o germário. Durante cada ciclo gonotrófico, um novo folículo se forma no germário.
$\mathrm{Na}$ segunda fase, o vitelo aparece ao redor do núcleo do oócito. Este desenvolvimento utiliza nutrientes acumulados na fase larval ou carboidrato de fontes tais como néctar de flores, ou a primeira alimentação de sangue. Quando este primeiro folículo está na segunda fase da ovogênese, um outro já se separou do germário. Sob condições normais, o desenvolvimento, além desta segunda fase, quando o folículo está em estádio II, não se processará sem que a fêmea obtenha um repasto sangüíneo. Em alguns casos, particularmente em climas temperados, as fêmeas de mosquitos não necessitam obter uma refeição de sangue antes de desenvolver seu primeiro lote de ovos. Tais fêmeas são denominadas autógenas, comparadas com aquelas que necessitam de sangue para desenvolver os ovos, que são chamadas anautógenas. Depois da primeira oviposição, as fêmeas autógenas normalmente necessitam de sangue para subseqüentes desenvolvimentos dos ovos (Clements, 1963).

Autogenia pode ser inferida se:

a) o número de fêmeas nulíparas (sem ovipositar) capturadas for muito pequeno ou,

b) se fêmeas grávidas ou subgrávidas forem capturadas e não mostrarem nenhuma evidência de ter obtido uma prévia alimentação de sangue.

$\mathrm{Na}$ terceira fase, após a obtenção de sangue, os ovos desenvolvem-se até à maturidade (Estádio III a V). Quando o ovo está pronto para ser colocado, um terceiro folículo sai do germário, e o segundo entra na segunda fase de desenvolvimento. Assim, numa fêmea grávida, é possível verem-se todas as três fases da ovogênese simultaneamente (Fig. 4).

Após a oviposição, a íntima, ao redor do ovo, e o pedicelo terminal, ficam grandemente estendidos na forma de um saco de parede fina, dentro do qual permanecem os restos dos trofócitos e do epitélio folicular. Algum tempo depois da oviposição, este saco começa a contrair-se lentamente. Posteriormente, este processo se acelera, e normalmente, 24 horas depois da oviposição, ele se completa, (dependendo da temperatura e espécie). 


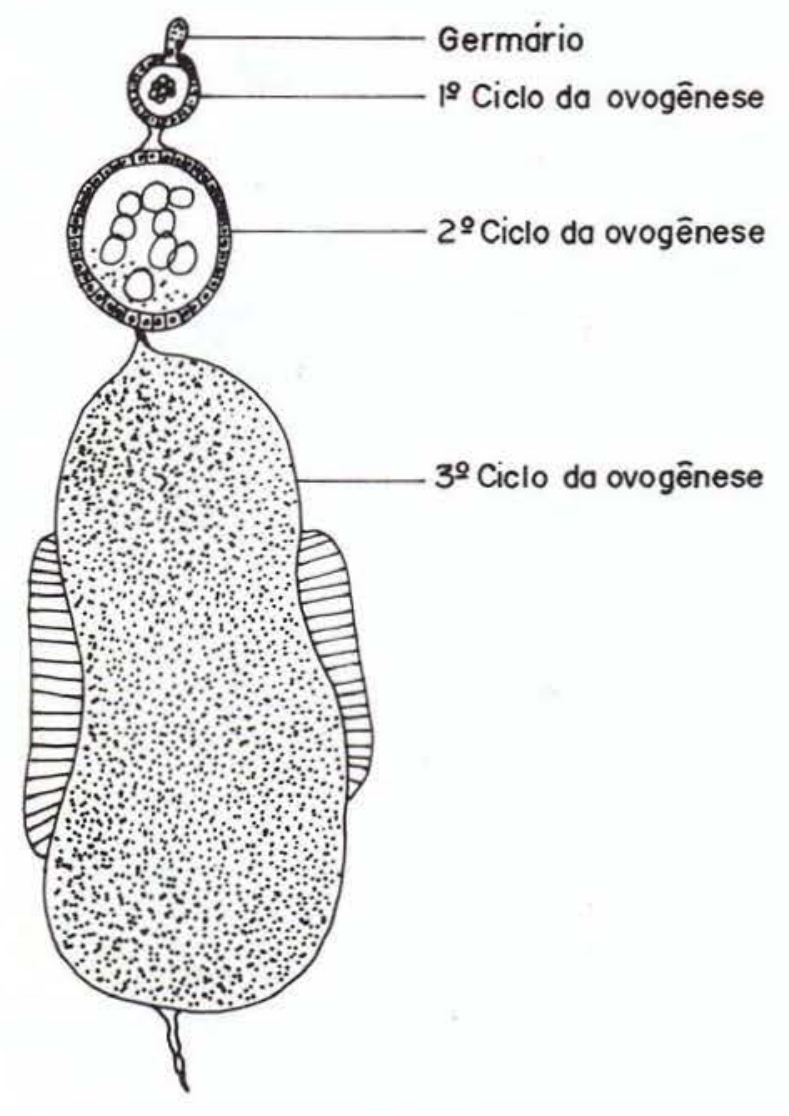

Fig. 4 - As três fases da ovogênese num ovariolo de uma têmea nulipara de Anopheles sp.

Inicialmente, o saco todo se contrai, e o pedicelo terminal separa-se. Seguindo-se a isto, a íntima se contrai, deixando apenas uma pequena dilatação no lugar onde o primeiro oócito se desenvolveu abaixo do próximo foliculo que irá desenvolver-se. O grau de contração foi usado por Corbet (1964), Samarawickema (1967), Charlwood \& Wilkes (1979) e Wilkes \& Charlwood (1979) para estimar o tempo entre oviposição e alimentação em várias espécies de mosquitos.

O processo de formação e retração do saco é repetido no segundo ciclo. Durante a contração do saco seguinte, que acompanha subseqüente oviposição, a dilatação formada depois da primeira oviposição se separa. Após esta, uma segunda é formada, onde o segundo folículo se desenvolveu. Assim, depois de duas oviposiçōes, permanecem duas dilatações (Fig. 5). Subseqüentes ciclos gonotróficos levam à formação de mais dilatações, sendo a dilatação mais perto do folículo em desenvoivimento, a mais recente. Esta dilatação é sempre maior que as anteriores, e contém mais inclusões. Quando o próximo óvulo se desenvolve e passa pelo pedicelo, as inclusões são carregadas fora e novos pigmentos são depositados. Assim, depois de cada ciclo gonotrófico, o comprimento do pedicelo aumenta pouco menos que a distância entre o germário e o folículo em desenvolvimento.

Durante qualquer ciclo gonotrófico, ocorre a ovogênese incompleta ou abortiva em alguns ovaríolos. Isso começa simultaneamente com a ovogênese normal e termina com a degene-

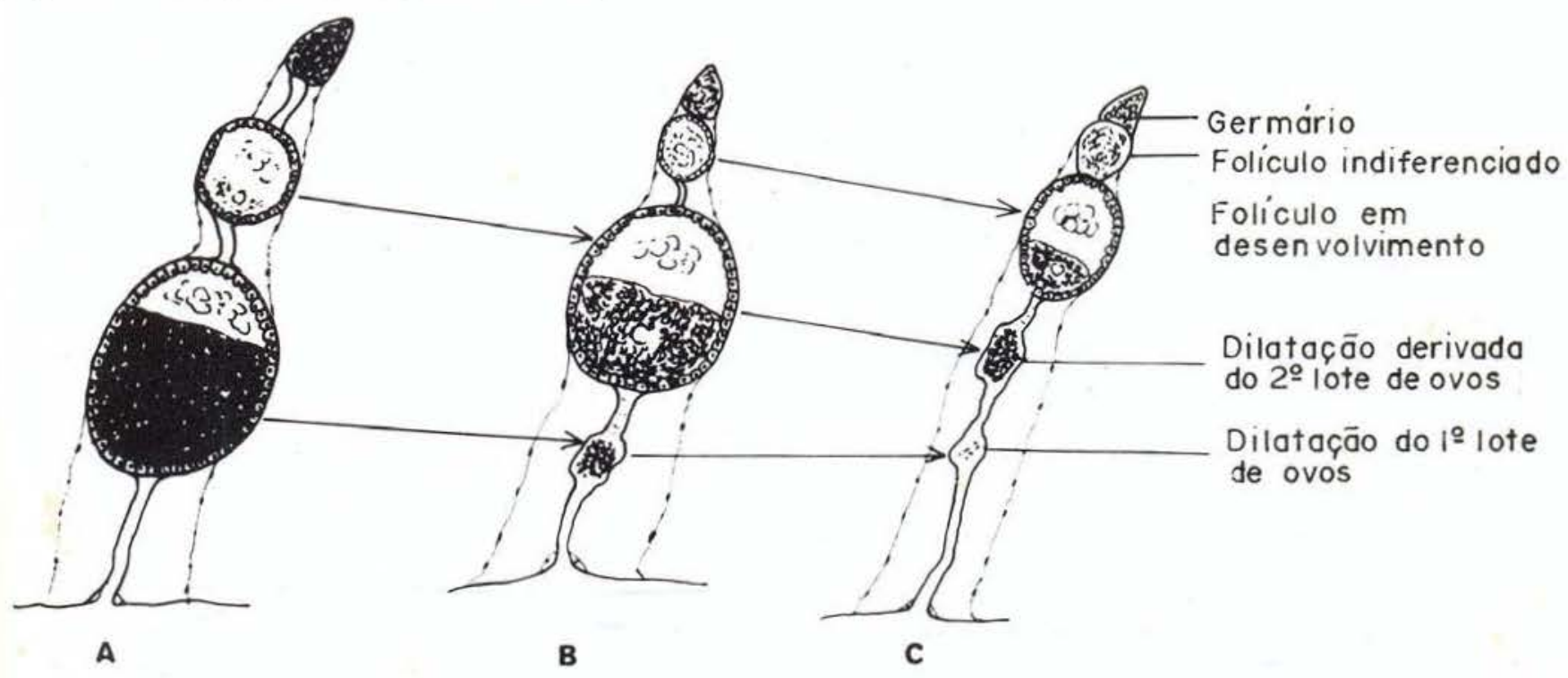

Fig. 5 - Mudanças na anatomia dos ovariolos de mosquitos após ovulações sucessivas 
ração do folículo em algum estádio intermediário do desenvolvimento. A degeneração pode ocorrer em qualquer estádio e o tamanho de acordo com o estádio, no qual o desenvolvimento se procedeu. Esta consiste na decomposição de grânulos do protoplasma do oócito, trofócitos e apitélio folicular, e, por fim, no vitelo acumulado. Ela ocorre, mais freqüentemente, nos primeiros estádios de desenvolvimento, e como resultado da decomposição do epitélio folicular, o folículo degenerado toma um formato irregular (Fig. 6) .

Se a degeneração ocorrer nos últimos estádios, a presença do material degenerado tornará improvável a maturidade do próximo folículo. Conseqüentemente, os ciclos subseqüentes terminarão em degenerações (Fig. 7). Se o número de oócitos degenerados em cada ciclo for constante, o número de degenerações aumentará com a idade. Assim, fêmeas velhas são facilmente reconhecidas, porque seus ovários são freqüentemente bem pigmentados: dadas as degenerações.

Usualmente, também há ovaríolos que se desligam do germário em cada ciclo gonotrófico, mas não iniciam qualquer desenvolvimento. Esses ovaríolos são denominados "anões" (do inglês "dwarf"), e parecem com as contas de um rosário. A cada ciclo gonotrófico abortivo, aumenta o comprimento por uma pequena dilatação. Os ovaríolos "anões" são importantes quando se está determinando a idade do inseto.

\section{O CICLO GONOTRÓFICO}

O ciclo gonotrófico tem sido definido como um processo fisiológico que consiste na digestão do sangue e no desenvolvimento dos ovários (WHO, 1975). Contudo, em uso mais comum, o termo cobre o espaço desde um repasto sangüíneo até o próximo, incluindo o tempo entre a oviposição e a procura do hospedeiro. Ainda outro termo denominado "ciclo de oviposição" é usado, e inclui todos os processos entre um repasto sangüíneo e o outro. Consideramos aceito o de uso mais comum.

Nos insetos que mostram concordância gonotrófica, o ciclo gonotrófico (de repasto sangüíneo a repasto sangüíneo) pode ser dividido em três partes :
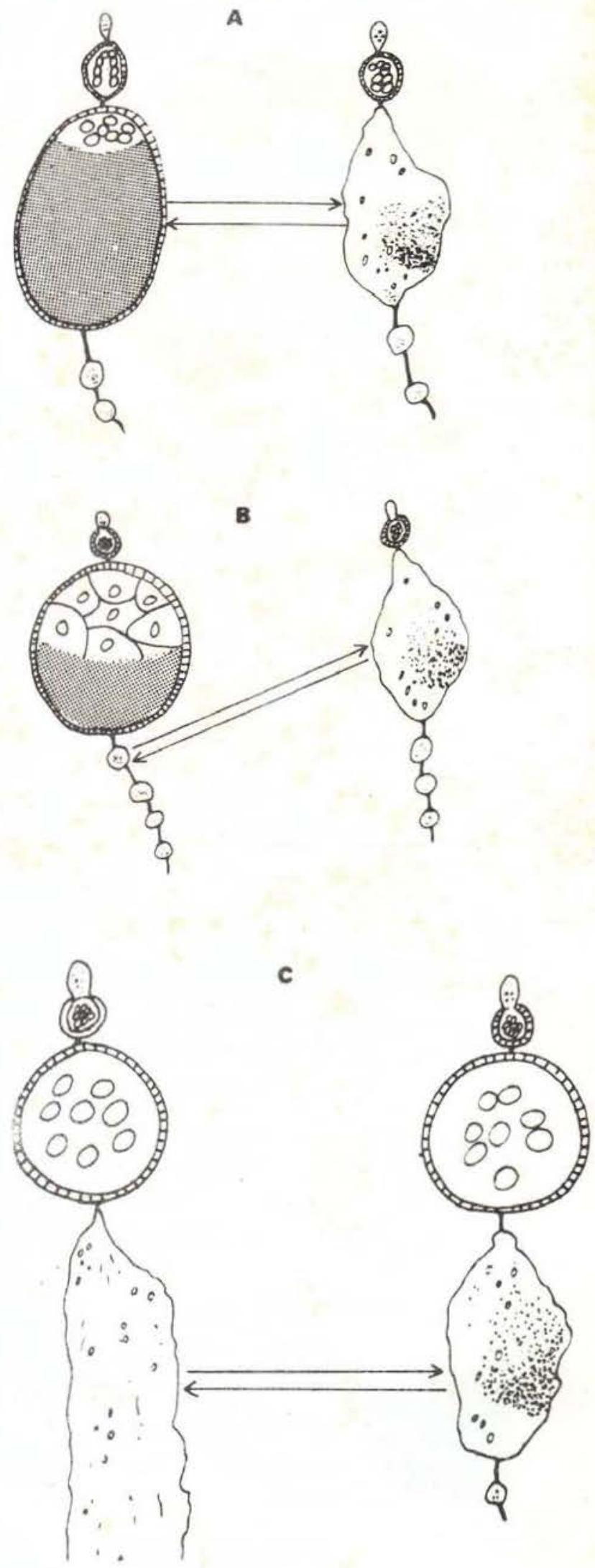

Fig. 6 - Determinação da idade fisiológica em mosquito através de ovariolos com folículos degenerando-se: A - Degeneração equivalente a um folículo em estádio IV; B - Degeneração equivalente a última dilatação; C — Degeneração equivalente ao estádio de saco. 


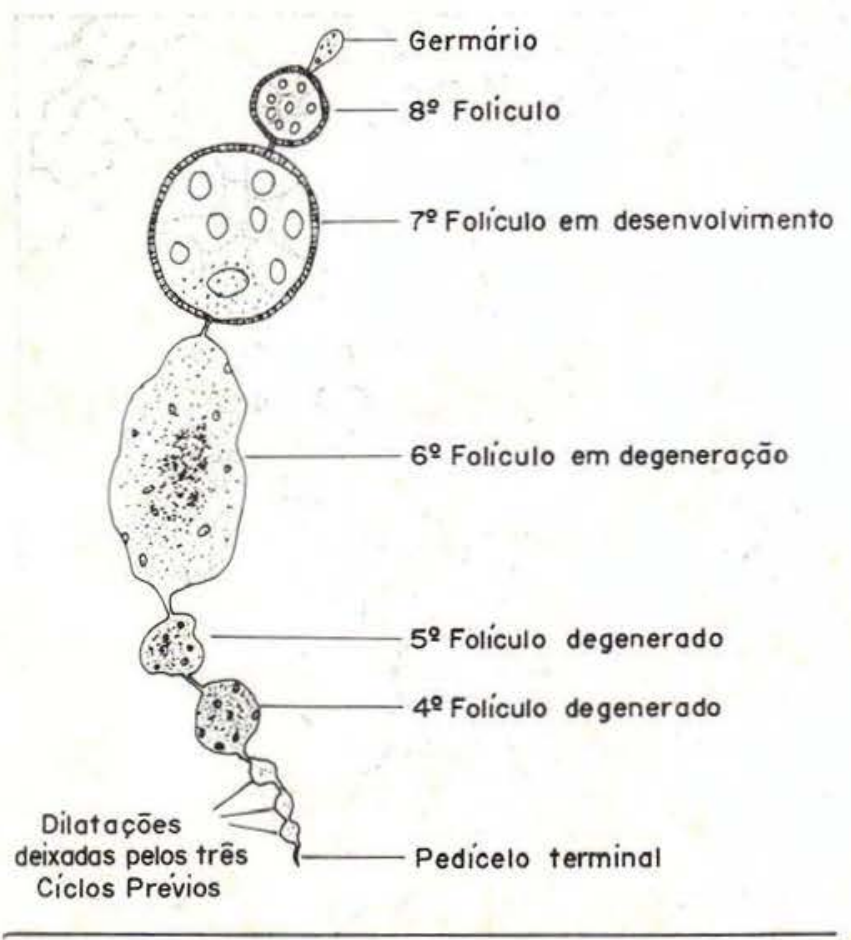

Fig. 7 - Diagrama mostrando a aparência de um ovaríolo hexaoníparo, com degeneraçōes após o terceiro ciclo gonotrófico.

1 - Procura de um hospedeiro e obtenção de sangue;

II - Digestão do sangue e maturação dos ovos;

III - Localização de um ponto ađiequado para a oviposição.

A duração de cada ciclo gonotrófico depende de vários fatores fisiológicos e ambientais. 0 processo de desenvolvimento do ovo, sendo dependente da temperatura, pode variar grandemente em climas temperados, onde as mudanças de temperatura são mais acentuadas que em regiões tropicais. Onde a temperatura é mais estável, a digestão do sangue e o desenvolvimento dos ovos tendem a processar-se num rítmo uniforme.

$\mathrm{Na}$ maioria das espécies, o tempo para desenvolver os ovos e o estádio de desenvolvimento podem ser determinados, observando se a aparência externa do abdômen da fêmea. Sella (1920) sugeriu que o processo de digestão de sangue pode ser dividido em sete estádios, e segundo a sugestão de Christophers (1911) para o desenvolvimento do ovo, estes estádios são ainda utilizados atualmente. Estes são mostrados na fig. 8 e caracterizados como se segue :

1 - Estômago sem sangue. Ovário não desenvolvido;

II - Fêmea com sangue fresco. O estômago cheio de sangue bem avermeIhado. Os dois últimos esternitos e os três últimos tergitos não apresen. tam sangue. Inicia-se o desenvolvimento dos ovários;

III - O sangue ainda retém sua coloração avermelhada. 2-2,5 esternitos e 4-5 tergitos estão livres de sangue. Os folículos neste estádio são encontrados no estádio II avançado de Chris. tophers;

A

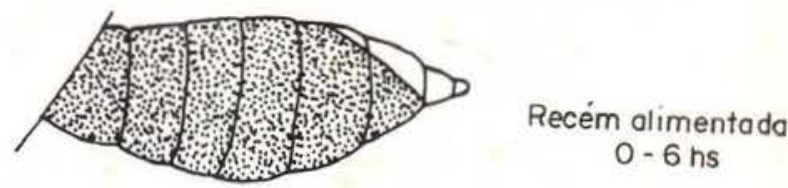

B

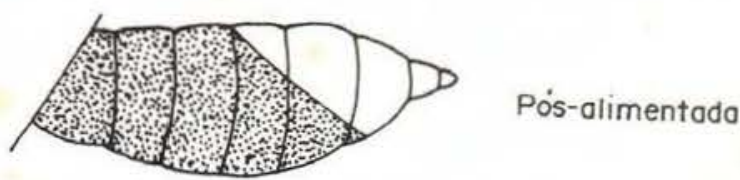

C

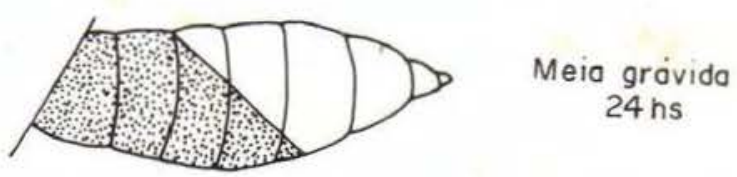

D

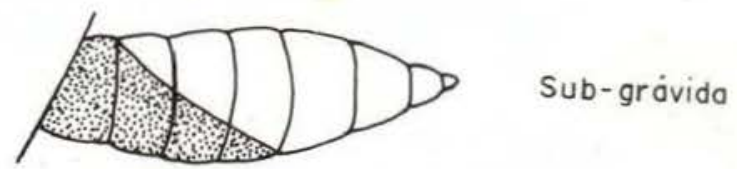

E

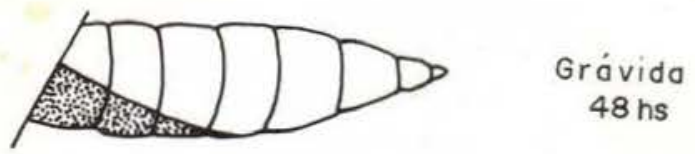

Fig. 8 - Aparência externa do abdomen de fêma de mosquito mostrando os diferentes estádios de desenvolvimento dos ovos. 
IV - O sangue no estômago toma cor preta. Os últimos 2,5-3 esternitơs e 5-6 tergitos estão livres dele. O folículo encontra-se em estádio III;

$\mathrm{V}$ - O sangue se mantém preto. Os últimos 2,5-3,5 esternitos e 6,5 tergitos estão livres dele. Os folículos nesta fase já alcançaram pelo menos o estádio IV;

$\mathrm{VI}$ - O sangue ainda se mantém preto e somente visível do lado ventral;

VII - O estômago apresenta-se livre de sangue. O abdômen está totalmente tomado pelos óvulos maduros no estádio V.

Outros fatores podem influenciar a duração do ciclo gonotrófico. O mosquito pode ter um período, não obrigatório, de descanso antes de voltar a alimentar-se. Isso aumenta a duração do ciclo gonotrófico e influência a importância epidemiológica da fêmea. A distância do local da oviposição até o hospedeiro, e a relativa facilidade com que o local de oviposição e os subseqüentes hospedeiros possam ser encontrados, também atingirão o tempo entre as alimentações. Se três espécies se alimentam sobre o homem e retornam ao mesmo lugar para o próximo repasto e, supondo que ocorra um rítmo uniforme de desenvolvimento do ovo, o tempo de retorno dependerá da localização do lugar da oviposição. No exemplo (Fig. 9), o Culex sp alimentar-se-á quase imediatamente após a oviposição, porque este local está situado próximo ao hospedeiro. O Aedes sp terá que fazer uma jornada maior para encontrar um local adequado para oviposição, enquanto que o Anopheles sp terá que voar, pelo menos, um quilômetro antes de colocar os ovos. Esses vôos compreenderão, certamente, a viagem de retorno.

É possível dar uma estimativa do tempo gasto depois que a fêmea ovipositou, através da observação do estádio do saco pedicelar deixado pela passagem do ovo. A fig. 10 mostra a contração progressiva do pedicelo folicular, através do qual passou um ovo. O grau de contração indica se a alimentação se seguiu, ou não, logo após a oviposição.

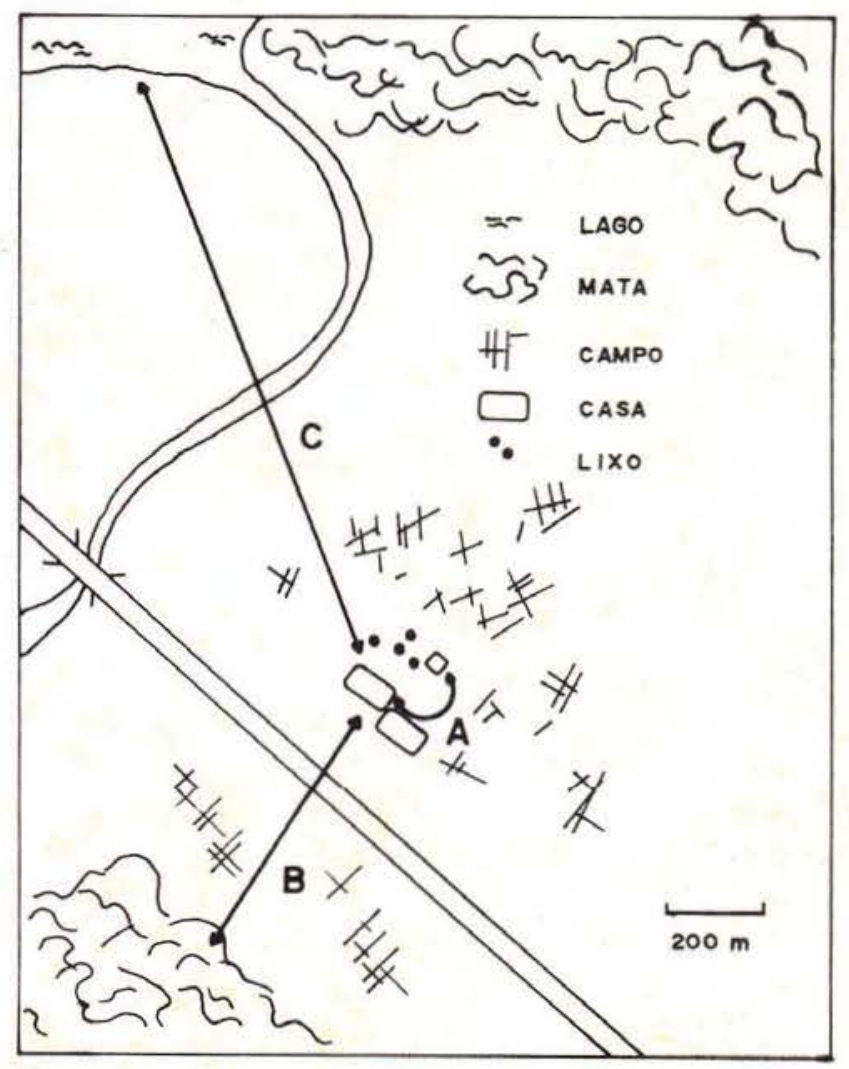

Fig. 9 - Diagrama mostrando os criadouros (locais de oviposições) relativo ao hospedeiro e a influência deste fator sobre o ciclo gonotrófico: A - Culex $s p$; B - Aedes sp; C - Anopheles sp.

Os estádios de saco: A, B, C, D, apresentam as seguintes características:

A - A porção terminal do ovariolo parece com um longo saco elástico, através do qual um ovo passou recente mente;

B - Sinais de contração aparecem na porção terminal do pedicelo, e o grau de elasticidade se reduz consideravelmente;

C - A porção terminal do pedicelo já está sensivelmente contraída;

D - A dilatação está reduzida ao tamanho normal.

Sob condições tropicais, os mosquitos apresentam saco em estádio 'B' dez a quatorze horas depois da oviposição, e o processo de contração até ' $D$ ' demora aproximadamente vinte e quatro horas. 


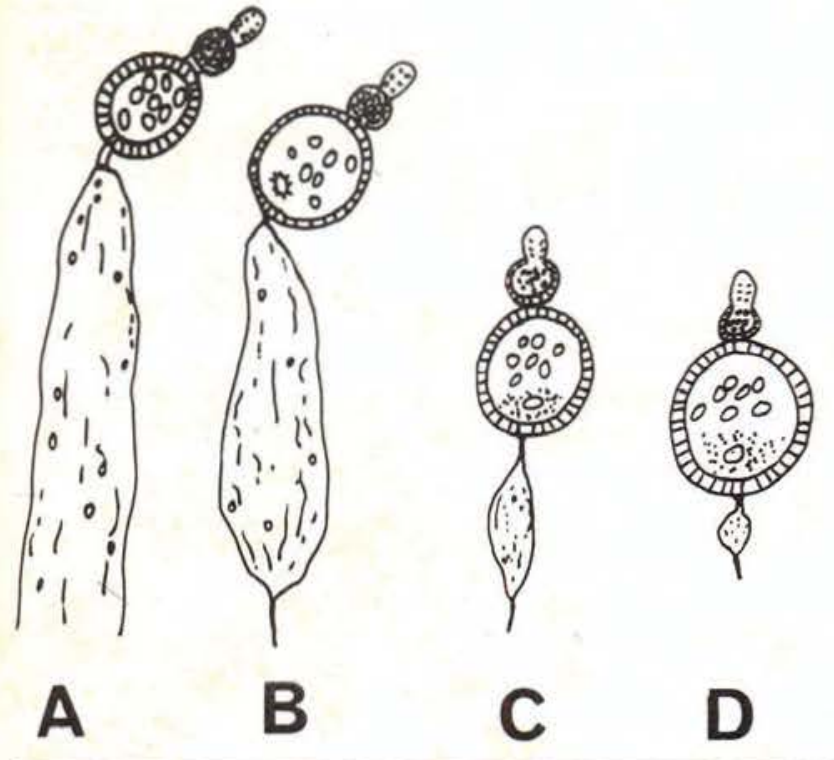

Fig. 10 - Diferentes stádios de contração do saco pedicelar.

Como é um processo contínuo, há certas áreas indeterminadas entre um estádio e outro. Há também uma certa irregularidade na velo. cidade de contração do saco. Todavia, é certo que fêmeas com sacos totalmente distendidos, tenham ovipositado há poucas horas, enquanto aquelas com dilatações já totalmente contraídas, tenham ovipositado, pelo menos, vinte e quatro horas antes.

Samarawickema (1967) registrou que $80 \%$ dos Culex quinquefasciatus (= fatigans) dissecados em Sri Lanka retornavam a alimentarse dentro de poucas horas depois da oviposição, enquanto Charlwood (1979) verificou que a maioria dos indivíduos dessa espécie capturada, quando se alimentava em Manaus, tinha descansado depois da oviposição. Assim, face ao aumento na duração do ciclo gonotrófico (4 dias em lugar de 3), uma fêmea trípara em Manaus pode ter quase tanta importância epidemiológica, quanto uma fêmea quadrípara em Sri Lanka.

As mudanças fisiológicas que se processam na fêmea durante o ciclo gonotrófico tem um profundo efeito no seu comportamento e. conseqüentemente, na sua viabilidade de ser capturada por métodos diferentes. Os hábitos de movimento e descanso de uma fêmea po- dem ser marcados por mudanças durante a digestão do sangue e o desenvolvimento dos ovos. Estes podem tornar-se bem evidentes antes da fase final do desenvolvimento ovariano, conduzindo à oviposição. $\mathrm{O}$ padrão pode variar entre espécies, e uma determinada fase pode ser mais representada por um método de captura e menos representada por outra. A viabilidade das diferentes fases no ciclo ainda pode ser atingida por mudanças na duração do ciclo, como as induzidas por mudanças sazonais e climáticas.

Uma completa refeição de sangue, na qual a fêmea obtém, pelo menos, seu próprio peso de sangue, é normalmente suficiente para a maturação dos ovários.

Em certas situações, na África, duas alimentações são necessárias para o desenvolvimento do primeiro lote de ovos. As fêmeas desses mosquitos com estas características, depois do primeiro repasto, são referidas como "pré-grávidas" (Gillies, 1954). A existência de parte da população que requer dois repasto antes de colocar o primeiro lote de ovos, pode ser determinada se fêmeas nulíparas forem capturadas, com folículos desenvolvidos além do estádio II.

Charlwood \& Wilkes (1979) encontraram aproximadamente $10 \%$ das fêmeas nulíparas de A. darlingi, capturadas quando sugavam sangue, em Aripuanã (Abril, 1978) com folículos em estádio III, indicando que as fêmeas já haviam obtido sangue previamente.

\section{MÉTODOS DE DETERMINAR A IDADE FISIOLÓGICA DE CULICIDAE}

Os seguintes métodos podem ser usados para determinar a idade fisiológica de mosquitos. Até certo grau, o método a ser usado depende da natureza dos resultados requeridos, do tipo e tamanho da amostra a ser examinada.

\section{a) Presença de ovos retidos}

Ocasionalmente a fêmea não coloca todos os ovos desenvolvidos durante um determinado ciclo gonotrófico, mesmo que estes tenham atingido a maturidade, de tal sorte que, a pre- 
sença de um ou poucos ovos maduros no ovário, indica que a fêmea já ovipositou e é onípara. No entanto, somente pequena porção da população mostra uma retenção de ovos. Esta característica, portanto, não dá um índice apurado da oniparidade numa população (Hitchcock, 1968 a) .

\section{b) Presença de ácaros fixados às fêmeas}

Gillett (1957) propôs que a presença de ácaros parasitos sobre a fêmea de mosquitos pode indicar nuliparidade, dado o ciclo de vida dos ácaros; muitos ácaros se fixam ao mosquito quando este eclode e se soltam por ocasião da primeira oviposição (Lanciani, 1979). Mullen (1974) fornece informações sobre todos os registros conhecidos de mosquitos parasitados por ácaros. Ele (Mullen, 1975) dá uma chave das ninfas (família e gênero) parasitas de mosquitos. Jalil \& Mitchell (1972) também descrevem em minúcias as principais diferenças entre os dois tipos de ácaros mais comuns, os aquáticos e os não aquáticos. Com acima de 20.000 observações sobre mais de dez espécies de mosquitos, Corbet $(1960,1962)$ concluiu que os ácaros são indicadores de nuliparidade, quando estão vivos. O mesmo (Corbet, 1970) disse que somente certos gêneros (tipos pionídeos) podem ser usados para esta determinação, fato este que Graham (1969) negligenciou quando disse que a técnica não era segura. Morris \& DeFoliart (1970) também registraram que a técnica era insegura, enquanto Jalil \& Mitchell (1972) opinaram que os ácaros, tipo pionídeos, gênero Arrenus, podem ser usados. Num estudo completo sobre ácaros parasitos de mosquitos no Paquistão, Reisen \& Mullen (1978) concluiram que os ácaros, particularmente Arrenus madruzi, não fornecem índice da oniparidade do hospedeiro

Não obstante, sendo a técnica segura, ou não, sua utilidade é duvidosa, pois o índice de parasitismo é freqüentemente muito baixo.

No Brasil, Charlwood \& Wilkes (1979) registraram 16 ácaros de $775 \mathrm{~A}$. darlingi examinados e 10 entre 1.127 A. triannulatus, dando uma taxa de $2,0 \%$ e $0,9 \%$ respectivamente.
Os ácaros são encontrados em outros grupos de Díptera, tais como, Culicoides sp, Stomoxys sp e Tabanidae. Pouco é conhecida a vaiidade em usar-se os ácaros para indicar a taxa de nuliparidade nestes grupos, porque a baixa taxa de infestação limita seu uso.

\section{c) Tamanho da ampola}

Mer (1932) foi o primeiro a descrever um método de determinar a idade das fêmeas de mosquitos, medindo as dimensões da ampola dos ovários. Ele descobriu que o tamanho aumenta quando o mosquito oviposita. Assim, uma vez, obtido o tamanho médio para diferentes idades, uma idéia pode ser obtida da idade da fêmea. Contudo, o método é laborioso e exis. te, em qualquer população, uma certa sobreposição entre as fêmeas nulíparas com ampolá grande, e fêmeas oníparas com ampola pequena (Gillies, 1958). As descobertas de Detinova (1962) e Polovodova (1949) têm conferido este método obsoleto. Entretanto, a aparência geral das ampolas podem fornecer bons indícios para idade dos mosquitos. A ampola e o oviduto de fêmeas oníparas contém uma grande quantidade de material pigmentado, enquanto insetos nulíparos a apresentam clara e elástica.

\section{d) Coloração verde e condições dos tubos de malpighi}

Logo após a eclosão, os mosquitos apresentam algumas características que podem ser usadas para determinar a presença de insetos muito jovens na amostra. Membros de ambos os sexos apresentam tubos de malpighi opacos na emergência. O estômago e o intestino contém mecônio, um excreta amarelado derivado do estádio pupal. Se o mosquito apresentar o tegumento claro, este excreta pode ser visto através da parede abdominal. O mesmo é excretado rapidamente e sua presença somente é útil para dectar insetos jovens na população.

Self \& Sebastian (1971) confirmaram os registros de De Meillon et al. (1967) de que Culex quinquefasciatus coletados logo após a emergência mostram uma distinta coloração 
verde, observando lateralmente o tórax e o abdômen. Isto desaparece, 72 horas após, e portanto pode ser usado como indicador válido para nuliparidade. Graham \& Bradley (1972) utilizaram esta característica para calcular a taxa diária de sobrevivência na mesma espécie.

A presença de músculos remanescentes também tem sido usada como indicador de nuliparidade em alguns mosquitos jovens (Rosay. 1961). Estes músculos são autolisados dentro dos áois primeiros dias da vida adulta.

Em Anopheles (Myzomia) gambiae e outros anofelinos africanos, as fêmeas recebem um plug gelatinoso no acasalamento (Gillies, 1956) para fertilização (Fig. 11). Este é absorvido dentro de 24-48 horas após a cópula. Assim, a presença do mesmo neste grupo de mosquitos, fornece uma indicação de nuliparidade, pois o acasalamento sempre ocorre antes da primeira oviposiçăo.

\section{e) Observação das traquéolas}

Os ovários de um mosquito têm um ricc suprimento de oxigênio, fornecido por uma rede de traquéias e traquéolas. Em fêmeas nulíparas que têm os folículos em estádio I ou II, as finas terminações das traquéolas apresentam-se enoveladas (fig. 12 a e b). Com o desenvolvimento dos ovos e o aumento do ovário, começa a haver o desenrolamento do enovelado, para formar uma rede dispersa (fig. $12 \mathrm{c}$ e d). Esta mudança é irreversível. Assim, o enovelamento terminal das traquéolas é uma indicação de que a fêmea é nulípara. O método para ver as traquéolas é fazer dissecaçōes com água destilada (nunca salina) e deixar secar ao ar. Quando o ovário seca, o ar entra pelas traquéias até às mais finas traquéolas, que se tornam claramente visíveis sob microscópio O ovário seco sobre a lâmina pode ser armazenado por um longo período tão logo sejam tomadas as precauções contra fungo. Este método descoberto por Detinova (1949) é excepcionalmente útil porque :

1) As dissecações podem ser feitas no campo e as análises realizadas em iaboratório;

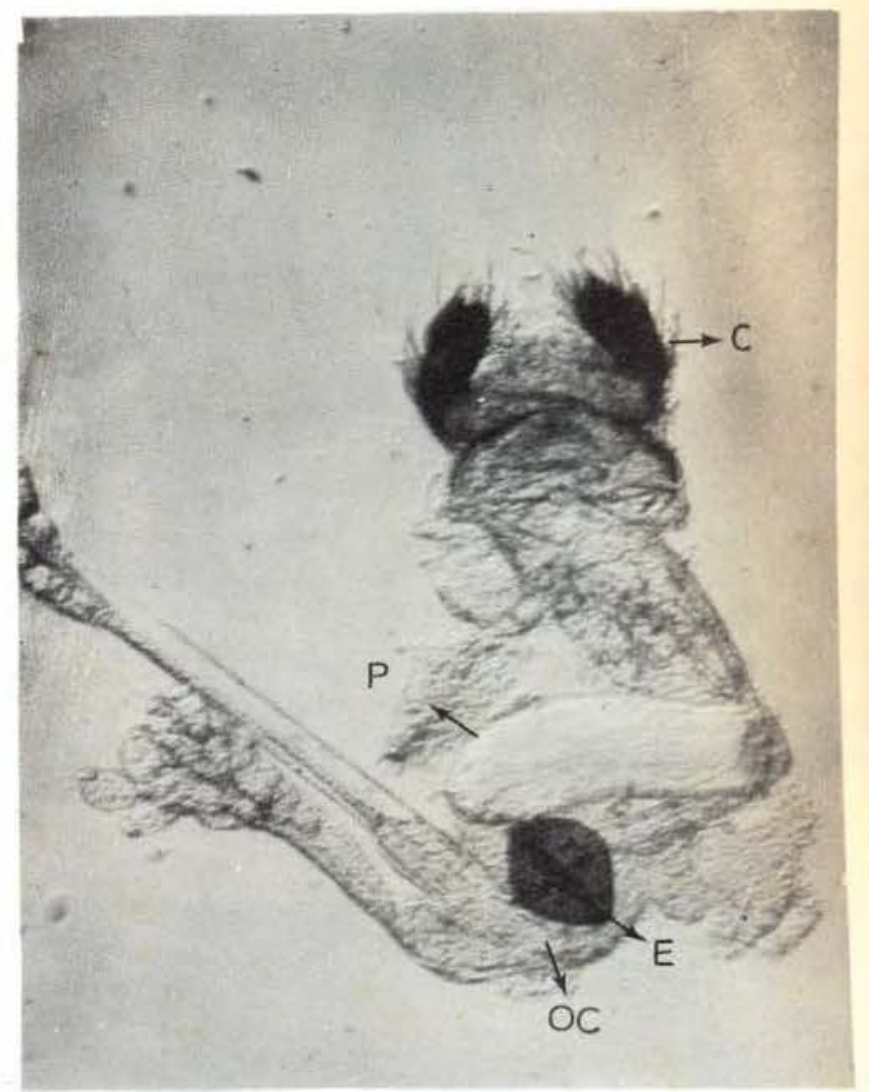

Fig. 11 - Plug gelatinoso em Anopheles gambiae indicando recente acasalamento: $E$ - espermateca; $\mathrm{OC}$ - oviduto comum; $\mathrm{P}$ - plug; $\mathrm{C}-$ cercos.

2) O material dissecado pode, sem muito problema, ser armazenado por longo período sem deterioração;

3) Nenhuma destreza especial é necessária para realizar a dissecação, podendo ser dissecados 200-300 insetos por dia. A técnica não pode ser usada nos mosquitos que desenvolveram os foliculos além do estádio II, pois o aumento da quantidade de vitelo tende a escurecer as traquéolas. Também, nos últimos estádios de desenvolvimento, as terminações das traquéclas já estăo estendidas, mesmo sendo uma fêmea nulípara. A técnica não faz distinção entre fêmeas que ovipositaram uma ou várias vezes.

Esta técnica é útil, quando grande número de insetos precisa ser dissecado. Quando um aspecto mais pormenorizado da estrutura da idade da população é necessário, usa-se o método desenvolvido por Polovodova (1949) e Detinova (1962) . 

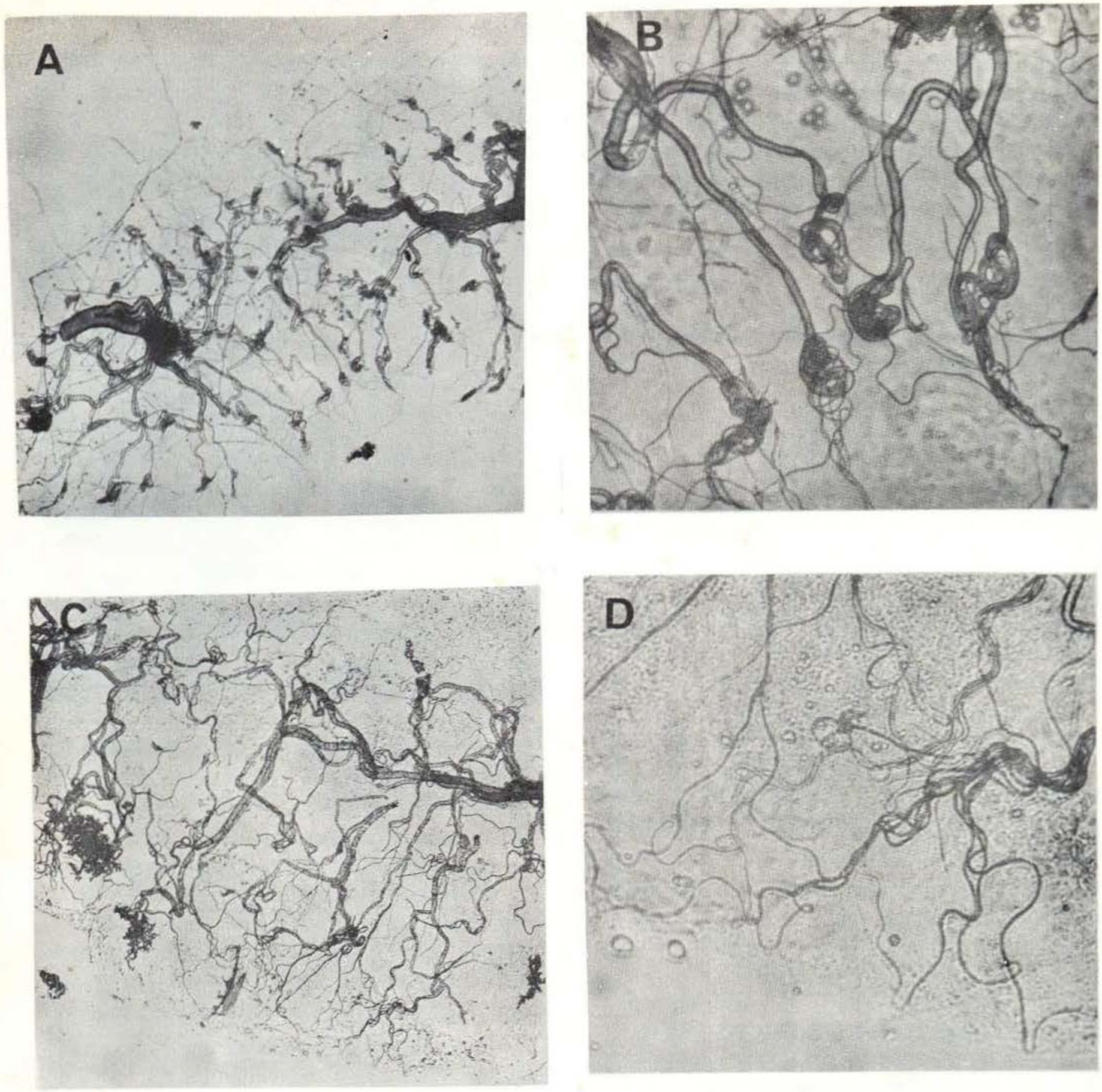

Fig. 12 - A-B - Aparência das traquéias e traquéolas de uma fêmea nulípara de A. darlingi. Notar as terminaçōes das traquéolas enoveladas; C-D - Aparência das traquéolas em fêmea onípara de A. darlingi.

f) Determinação da idade fisiológica e ob. servação do pedicelo ovariolar (método de Polovodova)

Um clara descrição do método de Polovodova foi feita por Gillies \& Wilkes (1965), a qual transcrevemos neste trabalho.

Nas espécies tropicais, muitos ovaríolos têm que ser observados, porque, no início da dissecação, é difícil de verificar-se o número exato das dilatações. Co. mo conseqüência, a principal diferença parece estar na nossa habilidade de construir um quadro de condiçōes dos ovaríolos, fornecido por olhadas rápidas em uma série de pedicelos, cada qual podendo ser estendido por questōes de segundo. O quadro mais claro foi obtido da seguinte maneira:

O ovário, a princípio, é estendido em direçōes opostas, dando uma idéia geral da sua condição, isto é, se é nulíparo ou se há pouco ou muito pigmento no ovário para indicar a presença de poucas ou muitas dilataçőes. Continua-se o processo de extensāo do 
ovário em direções diferentes, com minucioso cuidado. para qualquer indício da sua idade. Em alguns ovarío. los, podem ver-se, por exemplo, duas dilatações em um pedicelo, e três em outro. Posteriormente, podem parecer dois em um pedicelo, mas, sabendo que o inseto deve ser, pelo menos, tríparo, pode freqüentemente, discernir-se uma terceira dilatação que poderia ter passado despercebida. Posteriormente, ainda, podem observar-se rapidamente quatro dilatações. Assim, fica-se predisposto a aceitar uma quarta dilatação, ao invés de três, a qual, poderia ser n€gligenciada. Ovaríolos com folículos degenerados são certamente os mais fáceis de determinar-se. Uma contagem exata pode ser feita dos ovaríolos com degeneraçōes, e subseqüentemente será possivel observar-se o mesmo número de dilatações em ovariolos normais. Algo sobre iluminação:

A luz difusa do dia é melhor, embora a dissecação pode, se necessário, ser realizada com fluorescente, tungstênio, "strip light". O ângulo, no qual a luz incide sobre a preparaçăo é importante. Uma visão mais clara é obtida, usando-se a luz da margem do espelho. Isto é, com o espelho levemente afastado do centro tende a aumentar o contraste entre o conteúdo sólido de uma dilatação e o meio de dissecaçăo. É também, às vezes, útil a mudança de ângulo do espelho no cur. so do exame. Um auxílio a mais, na diagnose, foi a presença dos ovaríolos denominados "anões" (nāo desenvolvidos) (Detinova, 1962; Shipitsina, 1962), no qual não ocorreu nenhum desenvolvimento. O folículo nesse ovariolo permanece no estádio $\mathrm{N}$ e estão sujeitos a ser negligenciados na dissecação habitual. Apesar da quase completa ausência de desenvolvimento, esses folículos săo gerados em cada ciclo gonotrófico. Em fêmeas velhas, parecem com um cordão de bolotas muito translúcidas (menos que $50 \mathrm{~mm}$ de diâmetro) o qual, uma vez reconhecido, pode ser facilmente contado (Gil. lies \& Wilkes, 1965). (Fig. 13).

A técnica de Polovodova é delicada, e exige muito tempo, quando comparada com o exame

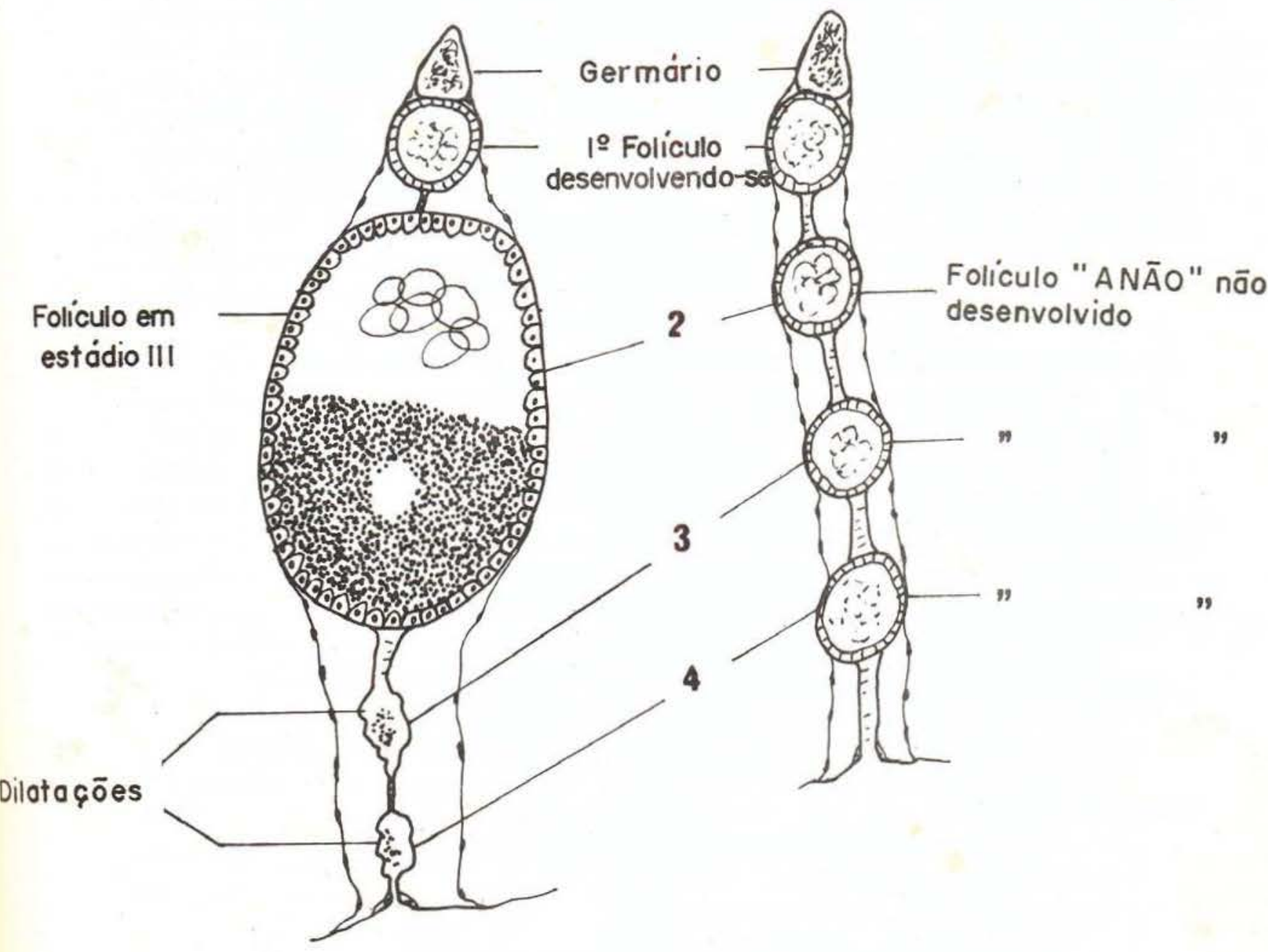

Fig. 13 - Aparência de um ovaríolo bíparo com folículos năo desenvolvidos. 
das traquéolas. Não obstante, a maior com. preensão obtida do ciclo de vida de um vetor potencial, freqüentemente faz com que a técnica seja vantajosa. Durante qualquer estudo, a formação das dilatações em séries, pode ser observada através de dissecações em laboratório de insetos de idade conhecida. Nem todos os pesquisadores foram capazes de observar estas dilatações seriadas. Giglioli (1965) não foi capaz de aplicar a técnica a $A$. melas, enquanto Wilkes (1968) e Snow \& Wilkes (1977) tiveram poucas dificuldades com esta espécie. Do mesmo modo, Rosay (1969) encontrou, depois de repetidas oviposições, as dilatações formadas em Culex quinquefasciatus, que tendiam a coalescer, enquanto Samarawickrema (1967) e Charlwood (1979) não tiveram dificuidades com esta espécie. Carpenter \& Nielsen (1965) registraram múltiplas dilatações em 18 espécies de Aedes examinadas por eles. Hitchcock (1968 a, b) também registrou múltiplas dilatações em $A$. quadrimaculatus.

Com o conhecimento da duração média entre os repastos sangüíneos, podem estimar-se a idade cronológica do inseto e seu verdadeiro potencial como vetor. A duração entre os repastos sangüíneos pode ser determinada através de experimentos de marca e recaptura (Gillies, 1961; Service, 1976), ou pela determinação do crescimento diário das camadas cuticulares dos apódemas (Schlein \& Gratz, 1972, 1973; Schlein, no prelo) em conjunto com dissecações ovariolares.

\section{DETERMINAÇÃo DE IDADE FISIOLÓGICA} EM OUTROS GRUPOS DE DIPTERA

\section{a) Simuliidae}

Simuliidae (piuns, borrachudos) são vetores da oncocercose na África e no Novo Mundo. Por esta razão, tem recebido considerável atenção dos entomologistas. Dois métodos de determinar a idade têm sido usado: estimando a diminuição do corpo adiposo e examinando os ovários para verificar as dilatações foliculares.

Davies (1957) mostrou que fêmeas nulíparas de $S$. ornatum tinham ampla quantidade de gordura, o que foi completamente utilizada durante o primeiro ciclo gonotrófico. Conseqüentemente, foi capaz de distinguir os indivíduos nulíparos dos oníparos. Também mostrou que, exceto para casos especiais, somente moscas com pouco corpo adiposo continham dilatações nos ovaríolos. Ducke (1968 a, b, 1975) utilizou esta condição do corpo adiposo para diferenciar os nulíparos dos oníparos em $S$. damnosum na África. Em contraste com Davies, que preferiu usar espécimens preservados em álcool (pois a "fixação dava a cor opaca e branca à gordura" e conseqüentemente fácil de ver-se) Ducke preferiu usar material fresco para as dissecações.

Como os culicídeos, os simulídeos mostram concordância gonotrófica, e seus ovários sofrem as mesmas mudanças gerais ocorridas em um Culicidae que obteve sangue e ovipositou. Essas mudanças foram descritas em pormenores por Ramirez-Perez et al. (1976). Depois da retirada do ovário em solução salina de $0,9 \%$, o exame é realizado da mesma maneira que nos mosquitos. Em fêmeas nulíparas, há um fino pedicelo terminal abaixo do primeiro folículo (Fig 14 a) onde em fêmeas oníparas existe um saco (imediatamente após a passagem do óvulo maduro, fig. 14 b) ou uma dilatação. Estendendo-se o ovário em direções opostas, algumas dilatações são grandes, mas, na maioria das vezes, são extremamente pequenas (Freden, 1964; Garms, 1975). Cóm estas características, o estado do ovário fornece indícios úteis para determinar a idade da fêmea. Nos ovários de fêmeas oníparas sem sangue, o oviduto inter. no apresenta-se expandido e translúcido e os ovários parecem ter estrutura frouxa, resultante da expansão da porção terminal dos ovaríolos, enquanto que em fêmeas nulíparas, sem sangue, os ovários são bem compactos. Várias dilatações foram observadas em simulídeos, na Rússia (Detinova, 1962), África (Wikes, 1976) e nos Estados Unidos (Magnarelli \& Cupp, 1977). A condição dos ovários e a presença de dilatações foliculares têm sido utilizadas para determinar a taxa de oniparidade na América do Sul (Ramirez-Ferez et al., 1976; Garms, 1975; Lacey \& Charlwood, no prelo). 

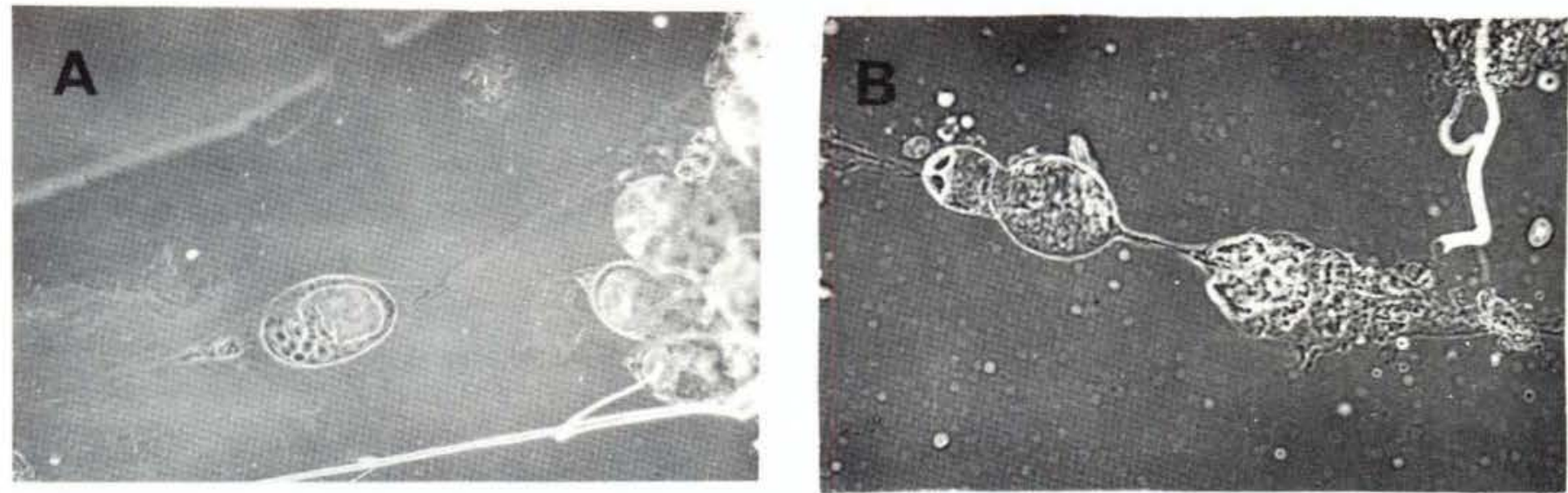

Fig. 14 - A - Ovaríolo de Simulium simplicicolor nulíparo; B - Ovaríolo de Simulium simplicicolor oníparo com saco em estádio "B" indicando que a oviposição ocorreu dentro das últimas 24 horas.

\section{b) Ceratopogonidae}

Ceratopogonidae são insetos pequenos que, não obstante, foram examinados com sucesso.

Linley (1965) escreveu as mudanças nos ovários de certos ceratopogonídeos, logo após completarem o ciclo gonotrófico. Como em outros grupos, indivíduos nulíparos têm o ová. rio transparente e compacto, no qual a bainha do ovário é altamente elástica. O exame do pedicelo e dos ovários a grandes aumentos (100-150x), mostram um pequeno tubo folicular claro sem nenhuma dilatação (Fig. 15 a). Imediatamente após a oviposição, vê-se uma estrutura saculiforme contendo pigmentos granulosos (Fig. 15 b). Este saco se contrai até deixar uma dilatação pigmentada bem definida. logo na frente do folículo em desenvolvimento (Fig. $15 \mathrm{c}$ ). Como em outros grupos, nem todos folículos de um lote de ovos se desenvolvem até à maturidade, degenerando-se em diferentes estádios, normalmente nos últimos (Duke, 1968 a, b) . Quando isto acontece, pode ver-se uma proporção de degenerações pigmentadas irregulares (Fig. $15 \mathrm{~d}$ ). Isto é muito útil para determinar a idade destes insetos. Os ovários dos oníparos também são mais frouxos e mais pigmentados que nos indivíduos nulíparos.

A presença de múltiplas dilatações em Culicoides griscens foi registrada por Glukho. va (1958) e suposta por Linley (1965) para Leptoconops bequaerti. Encontramos, durante a preparação desta revisão, fêmeas de Culicoides sp que pareciam ter duas distintas dilatações, contudo, confirmações definitivas de que se formam múltiplas dilatações são necessárias em fêmeas que tenham colocado dois lotes de ovos.

Dyce (1969) notou que certos pigmentos característicos se formam nos tecidos abdominais, durante o desenvolvimento de algumas espécies de Culicoides e outros ceratopogonideos. A pigmentação persiste após a oviposição. Assim, sua presença indica oniparidade Nelson \& Scrivani (1972) usaram isto para distinguir nulíparas de oníparas na isolação de arbovirus do complexo C. variipennis na California. Somente isolaram vírus dos lotes de moscas consideradas oníparas, indicando a eficiência do método. Ambos os trabalhos, no entanto, enfatizaram a necessidade inicial de diagnose em conjunto com a dissecação ovariolar. Este método tem a vantagem de classificar um grande número de insetos rapidamente, sem a necessidade de dissecaçăo. Excetuando-se a transmissão transovariana, espécimes oníparas somente necessitam de ser testados para isolação de vírus. Outra vantag€m é a habilidade de realizar infecções experimentais e trabalhos de transmissão com coletas no campo, o qual elimina a freqüente tarefa difícil de estabelecer colônias em laboratório. 

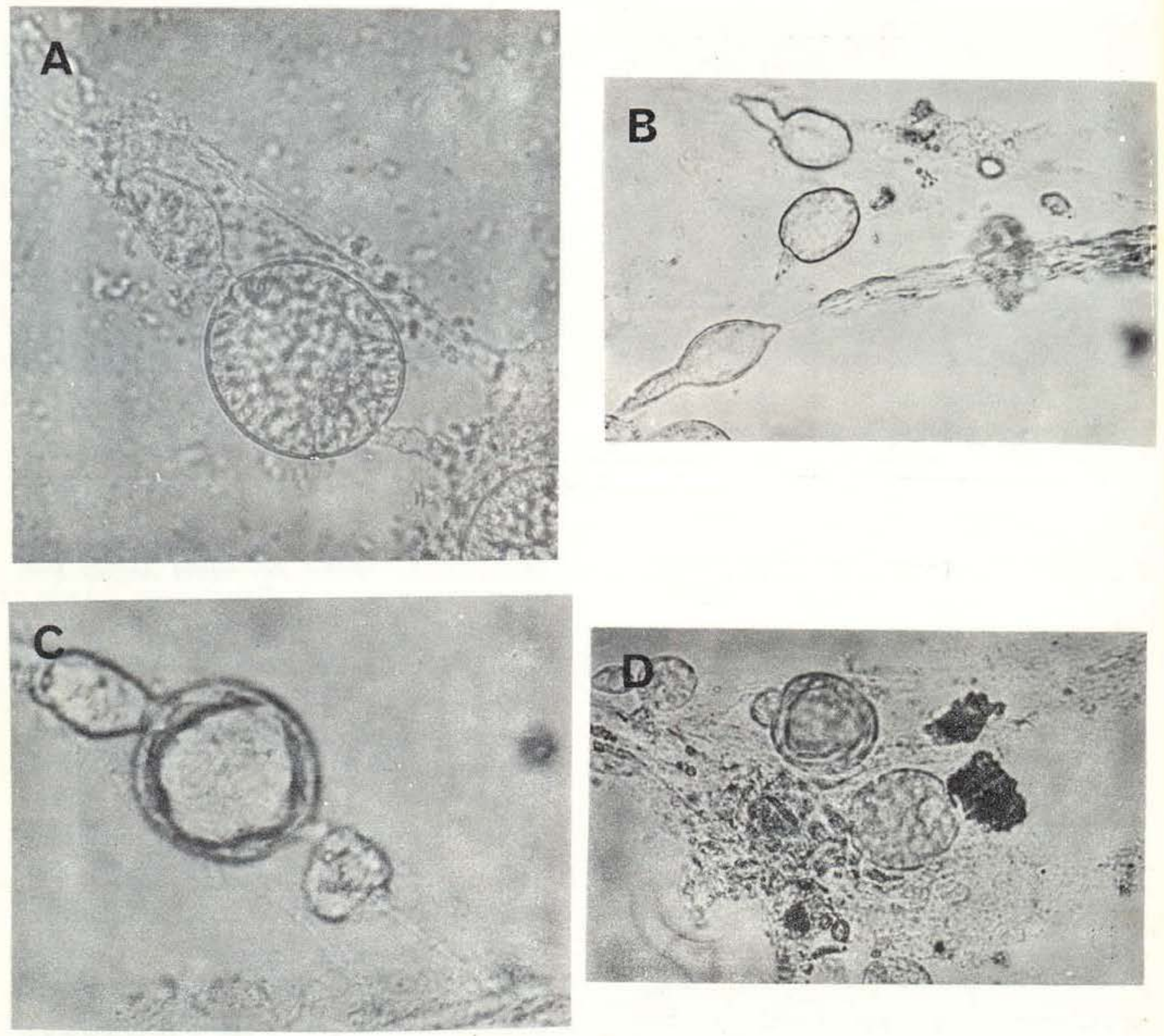

Fig. 15-A - Ovaríolo de Culicoides sp nulíparo; B - Ovaríolo de Culicoides sp com saco em estádio "A"; C - Ovariolo de Culicoides sp oníparo; D - Ovaríolo de Culicoides sp oníparo com folículos que se degeneraram antes da maturação.

\section{c) Phlebotomidae}

Como em ceratopogonídeos, a estimação da idade fisiológica de flebotomíneos está confinada, até o momento, à separação de fêmeas nulíparas e oníparas.

A idade fisiológica pode ser determinada, examinando-se os ovaríolos para presença de restos foliculares, degenerações ou óvulos retidos no estádio V (Fig. 16). Forattini (1962) dá uma excelente descrição da ovogênese e técnicas de dissecação usadas neste grupo, bem como Lewis et al. (1970). Cabe-nos dizer que a aparência e o tamanho dos ovários de flebotomíneos são muito semelhantes aos dos ceratopogonídeos. Cada dissecação consome muito tempo, e em face disto, a composição da idade em população natural, usando este método, é muito restrita.

Muitos investigadores usam a condição das glândulas acessórias como um indicador indireto de determinar a idade em flebotomíneos, como descrito por Forattini (1962). As glândulas acessórias enchem-se de material 
característico, durante a ovogênese. Parte desse material permanece, após a oviposição, indicando que a fêmea já ovipositou (Garnham \& Lewis, 1959; Lewis \& Minter, 1960; Forattini, 1962). Em particular, Lewis et al. (1970) verificaram que havia uma boa correlação entre amostras consideradas oníparas, depois do exame, e as glândulas acessórias; mas estas não são boas indicadoras em flebotomíneos. Conseqüentemente, como em qualquer investigação, onde a idade é taxada indiretamente, a confirmação de que as glândulas acessórias fornecem uma média precisa da população onípara poderia ser feita com referência ao número de dissecações do ovário.

\section{d) Tabanidae}

Os Tabanidae, assim como os outros grupos já mencionados, apresentam concơrdância gonotrófica. Como são insetos maiores, as dissecações através do método de Polovodova são mais facilmente realizadas e interpretadas, não necessitando de grandes aumentos (máximo de 40x) para observar-se o pedicelo e comprovar os corpos amarelos.

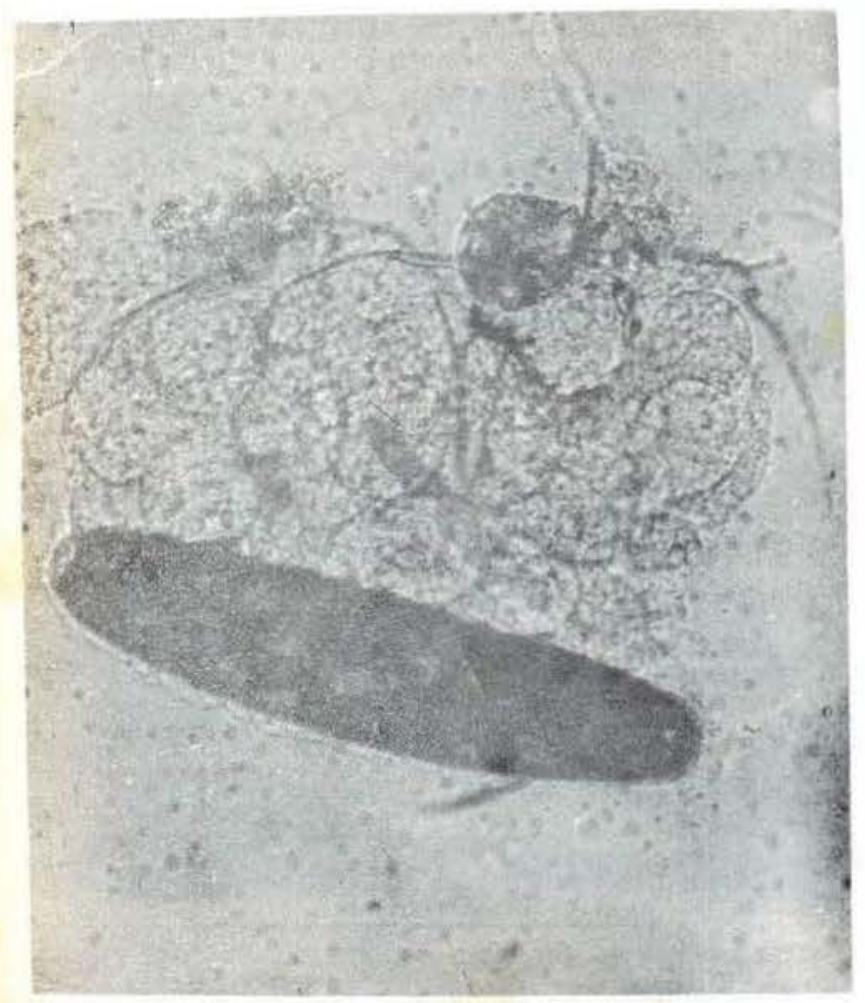

Fig. 16 - Ovário de Lutziomyia sp oníparo com folículo retido em estádio $\mathrm{V}$.
Giglioli (1963) e Rockel (1969) citam algumas soluções e corantes que podem ser utilizados para dissecação. Em nossos experimentos com Tabanidae, a solução de cloreto de sódio $0,9 \%$ (Jones, 1967) com uma pequena gota de detergente líquido (Duke, 1960) para reduzir a adesão entre os ovaríolos, mostrou-se muito eficiente.

Neste grupo, faz-se necessária a observação de um grande número de ovaríolos de ambos os ovários, porque diferentes estádios de desenvolvimento folicular e oniparidade podem existir (Magnarelli \& Pechumann, 1975). Já verificamos vários ovaríolos não se desenvolvendo quando os restantes estavam em estádio V de Christophers. Magnarelli (1976) não encontrou nenhuma evidência indicando maturação de alguns oócitos, enquanto outros permaneciam em estádio de descanço.

As dissecações são feitas em fêmeas recentemente capturadas ou podem ser realizadas posteriormente; para isso, é necessário que o material seja armazenado a $-12^{\circ} \mathrm{C}$. Thomas (1972) dissecou material até seis meses depois da captura, e os encontrou em condições perfeitamente normais. Para tanto, deve tomar-se o cuidado de não desidratar os indivíduos antes ou durante a estocagem.

A retenção de oócitos maduros é a mais óbvia indicação de que uma fêmea é onípara. Infelizmente, nem todas retém oócitos depois da oviposição. Somente pela retenção, não podemos saber o número de oviposições realiza. das. Thomas (1972) registrou $28 \%$ para Hybomitra nuda, Morris \& DeFoliart (1971) $30 \%$ para H. lasiophthalma, Magnarelli \& Pechumann (1975) $7,6 \%$ para Tabanus quinquevittatus, Lewis (1960) 14\% para Chrysops bicolor e Raybould (1967) 11\% para a mesma espécie.

Para observação dos ovaríolos, o espécime é imobilizado e colocado sobre sua superfície dorsal, puxando-se os dois últimos segmentos abdominais para longe do corpo, com a ajuda de estilete laminado. Os ovários são então separados, e sobre eles é depositada uma gota de solução salina $0,9 \%$, para, em seguida, fazer-se a observação do pedicelo e o estádio de desenvolvimento. 
Os ovários nulíparos apresentam o pedicelo claro sem nenhuma granulação ou dilatação (Fig. 17 a). Imediatamente após a oviposição. o pedicelo torna-se saculiforme com o tamanho aproximado do ovo recém-colocado (Fig. 17 b). Este saco se contrai, e os detritos do seu interior tornam-se conspícuos, formando um distin-
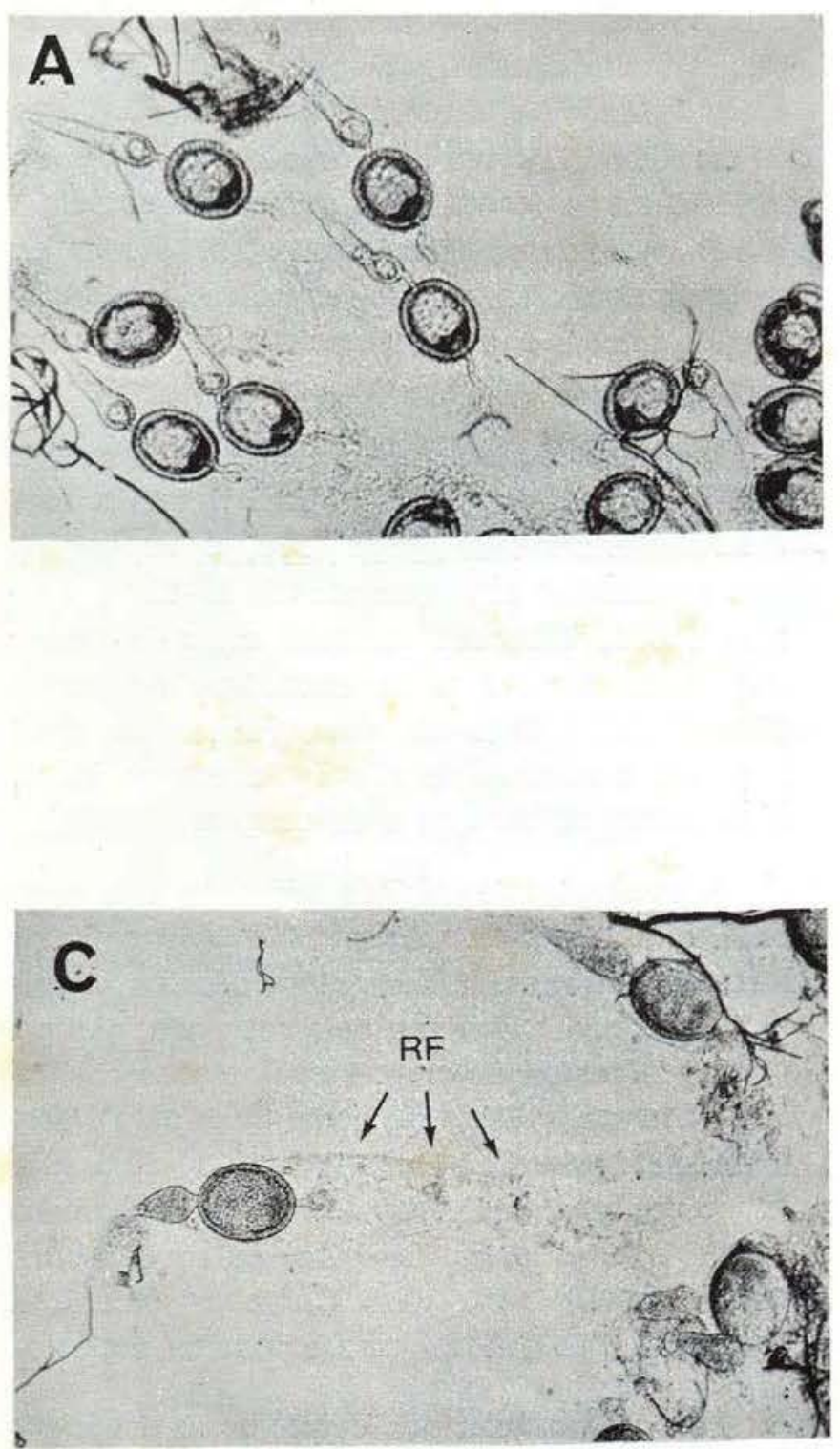

to "corpo amarelo" (Thomas, 1972) (Fig. $17 \mathrm{c}$ ), fenômeno idêntico ao que ocorre com Culicidae, Simuliiidae e Ceratopogonidae. Quando, no estádio de saco, se torna difícil a observação do número de dilatações, deve-se, portanto, procurar-se algum folículo que não tenha desenvolvido (Fig. 17 d), observando-se se há
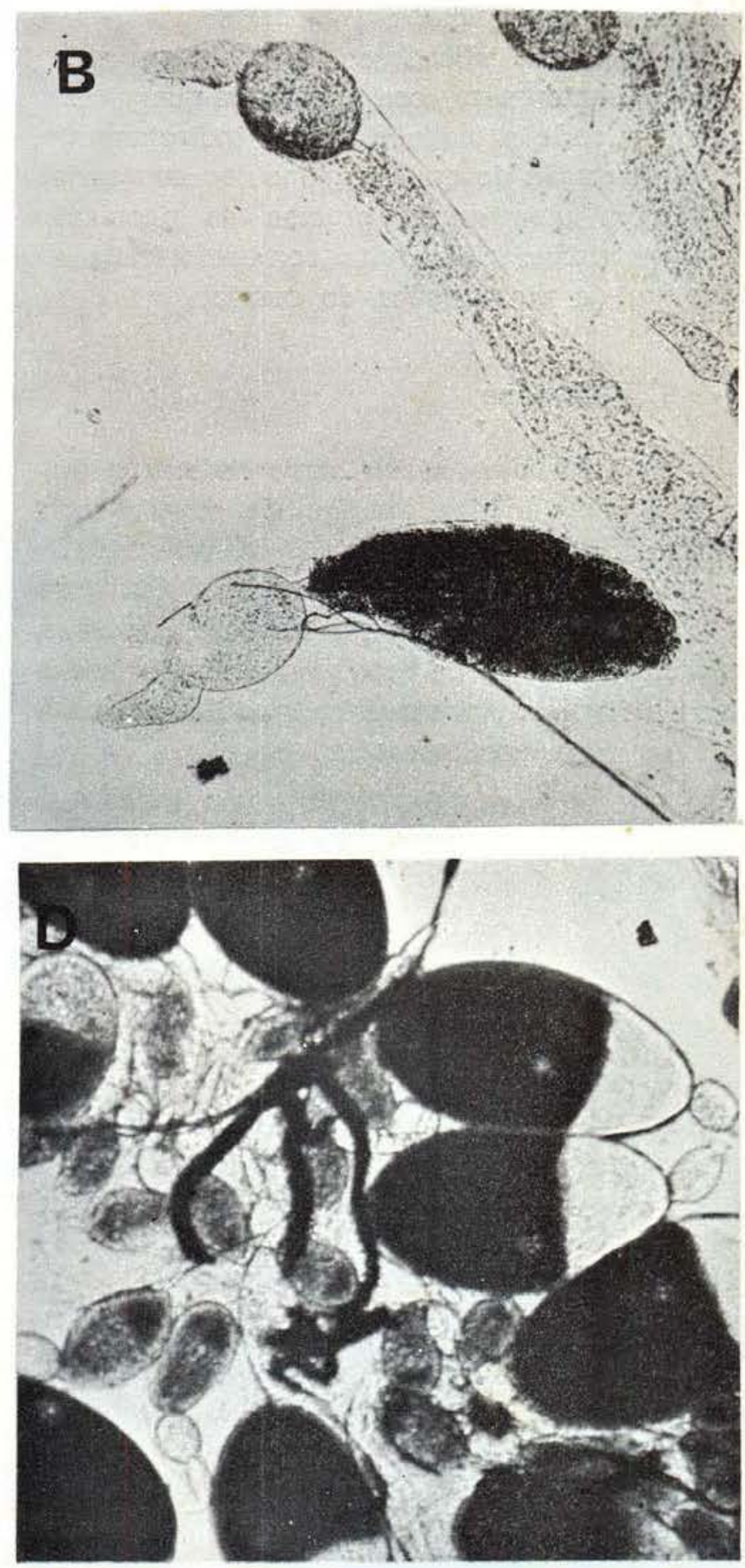

Fig. 17 - Ovaríolos de Tabanus dorsiger : A - folículo em estádio II; B - Ovaríolo de uma fêmea trípara, com restos foliculares (RF) bem definidos; $C$ - ovaríolo com saco em estádio " $A$ " (indicando recente oviposição) e outro com um folículo degenerado em estádio III-IV antes da maturação; D - ovaríolos com alguns folículos em estádio III e outros folículos năo desenvolvidos "anöes". Note-se o oócito dentro do vitelo nos folículos em desenvolvimento. 
ou não dilatações. Magnarelli \& Pechumann (1975) trabalhando com Tabanus quinquevittatus, verificaram que formações duvidosas de corpos amarelos podem ser uma fonte de erro no estudo da idade tisiológica.

Várias espécies de Tabanidae foram registradas como autógenas por vários autores: Thomas (1972), Rockel (1969), Anderson (1971), Troubridge \& Davies (1975).

O estádio de desenvolvimento do folículo, quando os indivíduos chegam para o repasto sangüíneo, normalmente se encontra em I-II ou II de Christophers. Duke et al. (1956) confir. maram esta observação, e sugeriram que o comportamento das fêmeas pode ser condicionado pelo estádio de desenvolvimento do ovário.

Anderson (1971), Thomas (1973), Magna. relli \& Pechumann (1975) e Magnarelli (1976) também registraram os mesmos resultados. Estádios N, III, IV e V dificilmente são encontrados nas fêmeas que chegam para tomar sangue. Page (1972) registrou estádios de desenvolvimento dos ovários bem avançados para quatro espécies de tabânidas colombianas, procurando sangue em uma vaca. Isto sugere que elas poderiam requerer mais de um repasto sangüíneo para o desenvolvimento total dos ovos, ou realizaram repastos incompletos. Duke et al. (1956) mostraram que a maturação dos ovos em Chrysops silacea segue o principio de "tudo ou nada"; quando a fêmea obtém quantidade insuficiente de sangue, nunca há qualquer maturação de poucos oócitos às expensas de outros.

Em Tabanidae, a alta proporção de uníparos em comparação com o inapreciável número de bíparos, sugere que as fêmeas apresentam vida curta e raramente iniciam o terceiro ciclo gonotrófico (Duke, 1960; Morris \& DeFoliart, 1971; Davies, 1969; Rafael, 1979).

Magnarelli \& Pechumann (1975) mantiveram Tabanus quinquevittatus alimentados com sacarose a $10 \%$ por 25 dias, mostrando que entre a oviposição e uma nova obtenção de sangue, as fêmeas podem viver um período de tempo suficiente para ser vetores de agentes patogênicos. A média de tempo entre a alimentação e a oviposição foi de 6,6 dias, variando de três até oito dias para $T$. quinquevittatus. Para Hybomitra lasiophthalma, observou-se a oviposição de seis até quatorze dias depois da alimentação. A temperatura foi pro. vavelmente a causa dessas diferenças (MacClain et al., 1975).

\section{AgradeCIMENTOS}

Os autores agradecem aos editores do Bulletin of entomological Research pela permissão de transcreverem parte do artigo original de Gillies \& Wilkes (1965), vol., 56.

\section{SUMMARY}

Physiological age grading methods for bloodsucking Diptera of medical importance which shows gonotrophic concordance are reviewed. In the first part the changes which occur in mosquitoes following a blood meal are cutlined and the theretical basis for age determination discussed. In the second part the methods applicable to Culicidae, Simuliidae, Phlebotomidae, Ceratopogonidae and Tabanidae are given. Extensive use of photographic material is made where this is a useful diagnostic aid in the interpretation of ovarian dissection.

\section{BIBLIOGRAFIA}

ANDERSON, J.P.

1971 - Autogeny and mating and their relationship to biting in the salt marsr deer-fly, Chrysops atlanticus (Diptera: Tabanidae). Ann. Ent. Soc. Am., 64: 1421-1424.

CARPENTER, M.J. \& NiELson, L.T.

1965 - Ovarian cycles and longevity in some univoltine Aedes species in the rocky mountains of Western United States, Mosq. News, 35: 127-134.

CHARLWOon, J.D.

1979 - Estudos sobre a biologia e hábitos alimentares de Culex quinquefasciatus em Manaus. Acta Amazonica, 9 (3): 463-470.

Charlwood, J.D. \& Wilkes, T.J.

1979 - Studies on the age-composition of samples of Anopheles darlingi Root (Diptera: Culicidae) in Brazil. Bull. Ent. Res., 69: 337-342.

CHRTSTOPHERS, S.R.

1911 - The development of the egg follicle in anophelines. Paludism, 2: 73-89.

Clements, A.N.

1963 - The physiology of Mosquitoes. Pergamon Press, OX. IX $+393 p p$. 
CORBET, P.S.

1960 - Recognition of nulliparous mosquitoes without dissection. Nature, Lond., 187: 525. 526.

1962 - The use of external characters to age grade adult mosquitoes (Diptera: Culicidae). Ent. Exp. Appl., 6: 215-233.

1964 - The time elapsing between oviposition and biting in the mosquito Mansonia (Coquillettidia) fuscopenata (Theobald). Proc. R. Ent. Soc. Lond. (A), 39: 108-110.

1970 - The use of parasitic water mites for age grading female mosquitoes. Mosq. News, 30: $436-438$.

DAVIES, L.

1957 - A study of the age of females of Simulium ornatum $\mathrm{Mg}$. (Diptera) attracted to cattle. Bull. Ent. Res., 48: 535-552.

\section{DAvies, J.B.}

1969 - Field preservation and storage of mosquitoes for laboratory studies. Mosq. News. 29: 259 .

De Metllon, B.; Sebastian, A. \& Khan, Z.H.

1967 - Time of arrival of gravid Culex pipiens fatigans at an ovipositios site, the oviposition cycle and the relationship between time of feeding and time of oviposition. Bull. Wld. Hith. Org., 36: 39-46.

Detinova, T.S.

1949 - Physiological changes in the ovaries of female Anopheles maculipennis. Med. Parazit., 18: $410-420$.

1962 - Age-grouping methods in Diptera of medical importance. Geneva, WHO, Monogr. Ser. (47): 1-216pp.

DUKE, B.O.L.

1960 - Studies on biting habits of Chrysops VII. The biting cycle of nulliparous and parous C. silacea and C. dimidiata (bomb form). Ann. Trop. Med. Parasitol., 54: 147-155.

1968 - Studies on factors influencing the transmission of Onchocerciasis IV. The biting cycles, infective biting density and transmission potencial of "forest" Simulium damnosum. Ann. Trop. Med. Parasitol., 62: 95-106.

$1968 \mathrm{~b}$ - Studies on factors influencing the transmission of Onchocerciasis V. The stages of Onchocerca volvulus in wild "forest" Simulium damnosum, the fate of the parasites in the fly and the age distribuition of the biting population. Ann. Trop. Med. Parasitol., 62: 107-116.
1975 - The diferencial dispersal of nulliparous and parous Simulium damnosum. Trop. Med. Pa. rasitol., 26: $88-97$.

Duke, B.O.L.; CREWE, W. \& BEesLey, W.N.

1956 - The relationship between the size of the blood-meal taken in by Chrysops silacea, the development of the fly's ovaries and the development of Loa loa take in with the biood-meal. Ann. Trop. Med. Parasitol., 50: 283-290.

DYCE, A.L.

1969 - The recognition of nulliparous and parous Culicoides (Diptera: Ceratopogonidae) with. out dissection. J. Aust. Ent. Soc., 8: 11-15.

FIIL, A.

1974 - Structural and functional modifications of the nucleus during oogenesis in the mos. quito Aedes aegypti. J. Cell. Sci., 14: 51-67.

1976 - Oogenesis in the malaria mosquito Anopheles gambiae. Cell. Tiss. Res., 167: 23-35.

FIIL, A. \& MENS, P.B.

1973 - The development, structure and function of modified synaptonemal complexes in mosquito oocytes. Chromosoma (Berl.), 26: 169187.

Forattini, O.P.

1962 - Entomologia Médica. Vol. 1. São Paulo, Fa culdade de Higiene e Saúde Pública. 662pp.

FREDEN, F.J.H.

1964 - On the determination of the approximate age of a blackfly (Diptera: Simuliidae) and its significance, Can. Ent., 96: 193.

GARMS, R.

1975 - Observations on Filarial infections and parous rates of antropophilic blackflies in Guatemala with reference to the transmission of Onchocerca volvulus. Trop. Med. Parasitol., 26: 169-182.

Garnham, P.C.C. \& Lewis, D.J.

1959 - Parasites of British Honduras with special reference to leishmaniosis. Trans. R. Soc. Trop. Med. Hyg., 53: $12-40$.

Garrett-Jones, C. \& Shidkawi, G.R.

1969 - Malaria vectorial capacity of a population of Anopheles gambiae. Bull. Wld. Hith. Org., 40: $531-545$.

GIgLIOLI, M.E.C.

1963 - Aids to ovarian dissection for age determination in mosquitoes. Mosq. News, 23: 156-159.

1965 - The problem of age determination in Anopheles melas Theo. 1903, by Polovodova's method. Cah. ORSTOM, ser. Entomol. Med., 3-4: 157-177. 
GILLETT, J.D.

1957 - Age analysis in the biting-cycle of the mosquito Taeniorhynchus (Mansonoides) africanus Theobald, based on the presence of parasitic mites. Ann. Trop. Med. Parasitol., 51: $151-158$

GILLIES, M.T.

1954 - The recognition of age-groups within populations of Anopheles gambiae by the pregravid rate and sporozoite rate. Ann. Trop. Med. Parasitol., 48: 58-74.

1956 - A new character for the recognition of nulliparous females of Anopheles gambiae. Bull. Wld. Hlth. Org., 15: 451-459.

1958 - A modified technique for the age-grading of Anopheles gambiae. Ann. Trop. Med. Parasitol., 52: 261-273.

1961 - Studies on the dispersion and survival of Anopheles gambiae Giles in East Africa by means of marking and release experiments. Bull. Ent. Res., 51: 89-127.

GILliES, M.T. \& WILKES, T.J.

1965 - A study of the age-compositions of populations of Anopheles gambiae Giles and A. funestus Giles in North-Eastern Tanzania. Bull. Ent. Res., 56: 237-262.

GLUKHOVA, V.

1958 - On the gonotrophical cycle of the midges genus Culicoides (Diptera: Heleidae) of the Karelian ASSR. Parasitol. Sbornik. Zool. Inst. Akad. Nank. SSSR, 18: 239-254.

Graham, P.

1969 - Age grading of mosquitoes from parasitic mites. Mosq. News, 29: 259-260.

Graham, J.E. \& BRAdley, I.E.

1972 - Changes in the age structure of Culex pipiens fatigans Wied. populations in Rangoon, Burma after intensive larviciding. J. Med. Ent., 9: 325-329.

Hiтснсоск, J.C.

1968a - Egg retention in Anopheles quadricamulatus Say in relation to physiological age. J. Med. Ent., 5: 8.

$1968 \mathrm{~b}$ - Age composition of a natural population of Anopheles quadrimaculatus Say (Diptera: Culicidae) in Maryland USA. J. Med. Ent., 5: 125-134.

JaLIL, M. \& Mrtchell, R.

1972 - Parasitism of mosquitoes by water mites. J. Med. Ent., 9: 305-311.

JONES, J.C.

1967 - Methods for dissecting mosquitoes. Mosq. News., 27; 76-82.
LANCIANI, C.A.

1979 - Detachment of parasitic water mites from the mosquito Anopheles crucians. J. Med. Ent., 15: 99-102.

LACEY, L.A. \& CharLwood, J.D.

- On the biting behaviour of some authrophilic Amazonian Simuliidae. Bull. Ent. Res., No prelo.

LEWIS, D.J.

1960 - Notes on Chrysops bicolor Cordier (Diptera: Tabanidae) in Tanganyika. Proc. Roy. Ent. Soc. Lond. (A), 35: 75-78.

Lewis, D.J.; Lainson, R. \& Shaw, J.J.

1970 - Determination of parous rates in Phlebotominae sandflies with special reference to Amazonian species. Bull. Ent. Res., 60: 209 219.

LEWIS, D.J. \& MINTER, D.M.

1960 - Internal structural changes in some African Phlebotominae. Ann. Trop. Med. Parasitol., 54: $341-365$.

LINLEY, J.R.

1965 - Changes in the ovaries of certain biting midges (Diptera: Ceratopogonidae) following completion of the gonotrophic cycle. Mlosq. News, 25: 306-310.

MACAN, T.T.

1950 - The anopheline mosquitoes of Iraq and North Persia. Mem. Lond. Sch. Hyg. Trop. Med., 7: 109-132.

Macclain, D.S.; Matrhyse, J.G. \& Kemen, M.J., JR.

1975 - Biological notes on three species of Tabanidae (Diptera) obtained during experiments on transmission of equine infections anemia of horses. J. Med. Ent., 12: 65-71.

MACDONALD, G.

1957 - The epidemiology and control of malaria. Ox. University Press, London, XIV + 201pp.

MAGNARELLI, L.A.

1976 - Physiological age of Tabanidae (Diptera) in eastern New York State, USA. J. Med. Ent., 12: $679-682$.

Magnarelli, L.A. \& Cupp, E.W.

1977 - Physiological age of Simulium tuberolum and Simulium venustul (Diptera: Simuliidae) in New York State, USA. J. Med. Ent., 13: 621-624.

Magnarelli, L.A. \& Pechumann, L.L.

1975 - Ovarian studies of Tabanus quinquevittatus (Diptera: Tabanidae). J. Med. Ent., 11: 687690. 
MER, G.G.

1932 - The determination of the age of Anopheles by differences in the size of the commom oviduct. Bull. Ent. Res., 23: 563-566.

1936 - Experimental study on the development of the ovary in Anopheles elutus Edw. (Diptera: Culicidae). Bull. Ent. Res., 27: 351-359.

MORRIS, C.D. \& DE FoliarT, G.R.

1970 - The physiological age of Wisconsin Aedes mosquitoes parasitized by water mites. J. Med. Ent., 7: 628.

1971 - Parous rates in Wiscosin mosquito populations. J. Med. Ent., 8: 209-212.

MUllen, G.R.

1974 - Acarine parasites of mosquitoes II. Illustrated larval Key to the families and genera of mites reportedly parasitic on mosquitoes. Mosq. News, 34: 183-195.

1975 - Acarine parasites of mosquitoes I. A critical review of al known records of mosquitoes parasitized by mites. J. Med. Ent., 12: 27-36.

Nelson, R.L. \& SCRIVANI, R.P.

1972 - Isolation of arboviruses from parous midges of the Culicoides variipennis complex, and parous rates in biting populations. J. Med. Ent., 9: 277-281.

NICHOLSON, A.J.

1921 - The development of the ovary and ovarian egg of a mosquito Anopheles maculipennis Meig. Quart. J. Micr. Sci., 65: 395-448.

PAGE, W.A.

1972 - Feeding behaviour and trypanosomatid infections of some tabanids and Culicidae in Colombia. J. Ent. (A), 47: 1-13.

PERRY, E.L.

1912 - Malaria in the Jeypore Hill tract and ajoining coast land. Paludism, 5: 32-40.

POLOVODOVA, V.P.

1949 - The determination of the physiological age of female Anopheles by the number of gonotrophic cycle completed. Med. Parazit., 18: $352-355$

RAfael, J.A.

1979 - Estudo da idade fisiológica de quatro populações de Tabanidae (Diptera) no Campus Universitário, Manaus, Brasil. Tese de mestrado, INPA/FUA, 71pp.

Ramirez-Perez, J.; Rossi, E.; Convit, J. \& RAmirez, A.

1976 - Importancia epidemiologica de las grupos de edaden la poblaciones de Simulium metallicum (Diptera: Simuliidae) en Venezuela. Bol. Of. Sanit. Panam., 80: 105-122.
RAYBOULD, J.N.

1967 - Studies on Chrysops bicolor Cordier (Dip. tera: Tabanidae) at Amani, Tanzania, with particular reference to feeding behaviour. Ann. Trop. Med. Parasitol., 61: 167-174.

Reisen, W.K. \& MUllen, G.R.

1978 - Ecological observations on acarine associates (Acari) of Pakistan mosquitoes (Diptera: Culicidae). Env. Ent., 7: 769-776.

ROCKEL, E.G.

1969 - Autogeny in deer fly, Chrysops fuliginosus (Diptera: Tabanidae). J. Med. Ent., 6: 140142.

ROSAY, B

1961 - Anatomical indicators for assessing the ages of mosquitoes: The teneral adult (Diptera: Culicidae). Ann. Ent. Soc. Am., 54: 526-529.

1969 - Anatomical indicators for assessing age of mosquitoes: Change in ovarian follicles. Ann. Ent. Soc. Am., 62: 605-611.

ROTH, T.F.

1966 - Changes in the synaptinemal complex during meiotic prophase in mosquito oocytes. Protoplasma (Wien), 61: 346-386.

SAMARAWICKEMA, W.A.

1967 - A study of the age-composition of natural populations of Culex pipiens fatigans Wied. in relation to the transmission of Filariosis due to Wuchereria bancrofti Cobbold in Ceylon. Bull. W.H.O., 37: 117-137.

SCHLEIN, Y.

- Age groups of anopheline malaria vectors (Diptera: Culicidae) by the cuticular growth lines. J. Med. Ent., No prelo.

Schlein, Y. \& GRatZ, N.C.

1972 - Age determination of some flies and mos. quitoes by daily growth layers of skeletal apodemes. Bull. W.H.O., 47: 71-76.

1973 - Determination of the age of some anopheline mosquitoes by daily growth layers of skeletal apodemes. Bull. W.H.O., 49: 371375 .

Self, L.S. \& Sebastian, A.

1971 - A high incidence of green colouration in newly emerged adult populations of Culex pipiens fatigans in Rangoon, Burma. J. Med. Ent., 8: 391-393.

Sella, M.

1920 - Relazione della campagna anti-anofelica di Fiumicino (1919) con speciale riguardo alla biologia degli Anofelied agli Anofeli infetti. Ann. Igiene, 30: Supp. 85 
SERVICE, M.W.

1976 - Mosquito Ecology, Field sempling methods. Applied Science Publishers Ltd. London., 583pp.

SHIPITSINA, N.K.

1962 - On the gonotrophic cycle and age condition of populations of bloodsucking flies (Diptera, family Simuliidae) in the vicinity of Krasnoyarsk. Med. Parasit., Moscow, 31: 18-29.

SNOW, W.F. \& WILKES, T.J.

1977 - Age composition and vertical distribuition of mosquito populations in the Gambia, West Africa. J. Med. Ent., 13: 507-513.

THOMAs, A.W.

1972 - Physiological age structure of adult tabanid populations (Diptera: Tabanidae) in Alberta, Canada. J. Med. Ent., 9: 295-300.

1973 - Follicle developmental stages in bloodsucking horseflies (Diptera: Tabanidae) in Alberta, Canada. J. Med. Ent., 10: 325-328.
Troubridge, D.A. \& DAvies, D.M.

1975 - Seasonal changes in physiological age composition of tabanid (Diptera) populations in southern Ontario. J. Med. Ent., 12: 453 457.

WILKES, T.J.

1968 - The application of Polovodova's technique to the study of Anopheles melas. Trans. R. Soc. Trop. Med. Hyg., 62: 470 .

1976 - The application of advanced age-grading tecniques to mosquitoes. Thesis submitted for fellowship of the Institute of Science Technology. England, 39pp.

WILKES, T.J. \& CHARLWOOD, J.D.

1979 - A rapid gonotrophic cycle in Chagasia bonneae from Brazil. Mosq. News, 39: 137139.

World Health ORganization

1975 - Manual on practical entomology in Malaria. Part I. W.H.O., Geneva. Offset N. 13, 160pp.

(Aceito para publicação em 20/02/80) 